\title{
Multi-Organ Protective Effects of Curcumin Nanoparticles on Drug-Induced Acute Myocardial Infarction in Rats with Type 1 Diabetes Mellitus
}

\author{
Paul-Mihai Boarescu 1,2,+(D), Ioana Boarescu 3,4, Adriana Elena Bulboacă ${ }^{1}$, Ioana Corina Bocsan ${ }^{2}$, \\ Raluca Maria Pop ${ }^{2}$, Dan Gheban ${ }^{5,+} \mathbb{D}$, Ruxandra-Mioara Râjnoveanu ${ }^{6} \mathbb{D}$, Armand Râjnoveanu ${ }^{7}$ (D), \\ Ştefan Horia Roşian ${ }^{8,9, *(D)}$, Anca Dana Buzoianu ${ }^{2}$ ad and Sorana D. Bolboacă $^{3}$ (D)
}

1 Department of Pathophysiology, Iuliu Haţieganu University of Medicine and Pharmacy Cluj-Napoca, Victor Babeș Street, No. 2-4, 400012 Cluj-Napoca, Romania; boarescu.paul@umfcluj.ro (P.-M.B.); adriana.bulboaca@umfcluj.ro (A.E.B.)

2 Department of Pharmacology, Toxicology and Clinical Pharmacology, Iuliu Haţieganu University of Medicine and Pharmacy Cluj-Napoca, Gheorghe Marinescu Street, No. 23, 400337 Cluj-Napoca, Romania; corinabocsan@yahoo.com (I.C.B.); raluca_parlog@yahoo.com (R.M.P.); abuzoianu@umfcluj.ro (A.D.B.)

3 Department of Medical Informatics and Biostatistics, Iuliu Haţieganu University of Medicine and Pharmacy Cluj-Napoca, Louis Pasteur Street, No. 6, 400349 Cluj-Napoca, Romania; ioana.boarescu@gmail.com (I.B.); sbolboaca@umfcluj.ro (S.D.B.)

check for updates

Citation: Boarescu, P.-M.; Boarescu, I.; Bulboacă, A.E.; Bocșan, I.C.; Pop, R.M.; Gheban, D.; Râjnoveanu, R.-M.; Râjnoveanu, A.; Roşian, Ş.H.; Buzoianu, A.D.; et al. Multi-Organ Protective Effects of Curcumin Nanoparticles on Drug-Induced Acute Myocardial Infarction in Rats with Type 1 Diabetes Mellitus. Appl. Sci. 2021, 11, 5497. https://doi.org/ 10.3390/app11125497

Academic Editors: Gregorio Peron and Jan Hošek

Received: 21 May 2021

Accepted: 11 June 2021

Published: 14 June 2021

Publisher's Note: MDPI stays neutral with regard to jurisdictional claims in published maps and institutional affiliations.

Copyright: () 2021 by the authors. Licensee MDPI, Basel, Switzerland. This article is an open access article distributed under the terms and conditions of the Creative Commons Attribution (CC BY) license (https:// creativecommons.org/licenses/by/ $4.0 /)$.
4 Department of Neurology, County Emergency Hospital of Zalău, Simion Bărnuțiu Street, No. 67, 450129 Zalău, Romania

5 Department of Pathological Anatomy, Iuliu Haţieganu University of Medicine and Pharmacy Cluj-Napoca, Clinicilor Street, No. 3-5, 400006 Cluj-Napoca, Romania; dgheban@gmail.com

6 Department of Pneumology, Iuliu Haţieganu University of Medicine and Pharmacy Cluj-Napoca, B.P. Hașdeu Street, No. 6, 400371 Cluj-Napoca, Romania; andra_redro@yahoo.com

7 Department of Occupational Medicine, Iuliu Haţieganu University of Medicine and Pharmacy Cluj-Napoca, Louis Pasteur Str., No. 3-5, 400349 Cluj-Napoca, Romania; armand.rajnoveanu@umfcluj.ro

8 “Niculae Stăncioiu” Heart Institute Cluj-Napoca, Calea Moților Street, No. 19-21, 400001 Cluj-Napoca, Romania

9 Department of Cardiology—Heart Institute, Iuliu Haţieganu University of Medicine and Pharmacy Cluj-Napoca, Calea Moților Street, No. 19-21, 400001 Cluj-Napoca, Romania

* Correspondence: dr.rosianu@gmail.com; Tel.: +40-740-566-171

+ These authors contributed equally to this work.

Abstract: The objectives of this study were to investigate the cardio-protective, hepatoprotective and nephroprotective effects of curcumin nanoparticle (NC) pretreatment compared to conventional curcumin (CC) on acute myocardial infarction (AMI) in rats with type 1 diabetes mellitus (T1DM). Fifty-six Wister Bratislava rats were divided into eight groups. The first four groups- $\mathrm{C}$ (control group), AMI (group with AMI), T1DM (group with T1DM), and T1DM-AMI (group with T1DM and AMI) - received only saline (S) during the whole experiment. Two groups-S-T1DM-CC-AMI and S-T1DM-NC-AMI-were pretreated with S before T1DM induction. The S-T1DM-CC-AMI group received CC (200 mg/Kg bw (bw-body weight)) after T1DM induction, while the S-T1DM-NCAMI group received NC (200 mg/Kg bw) after T1DM induction. the CC-T1DM-CC-AMI group received CC (200 $\mathrm{mg} / \mathrm{Kg} \mathrm{bw})$ during the whole experiment. Similarly, the NC-T1DM-NC-AMI group received NC $(200 \mathrm{mg} / \mathrm{Kg}$ bw) over the entire experiment. T1DM was induced on day 7 using a single dose of streptozotocin (STZ). AMI was induced with isoproterenol (ISO) on day 22. Both curcumin formulations, CC and NC, prevented the following electrocardiographic changes: prolongation of the QRS complex, enlargement of QT and QTc intervals, and ST-segment elevation. Glucose levels and lipid profile parameters were reduced up to 1.9 times, while C-peptide serum levels were increased up to 1.6 times in groups that received CC or NC. Liver function parameters (aspartate transaminase, alanine transaminase) and kidney function parameters (creatinine, urea) were reduced 4.8 times, and histological changes of liver and kidney tissue were improved by CC or NC administration. Pretreatment with NC proved significantly higher cardioprotective, hepatoprotective and nephroprotective effects in the case of AMI in T1DM. 
Keywords: curcumin; nanoparticules; cardio-protection; hepatoprotection; nephroprotection

\section{Introduction}

Cardiovascular disease represents a global public health problem and the leading cause of death. In 2008, the World Health Organization experts stated that cardiovascular diseases are the cause of 17.3 million deaths annually, of which 7.3 million are due to myocardial infarction, 6.2 million due to stroke, and 9.4 million through the direct involvement of hypertension [1]. Annually, cardiovascular diseases cause four million deaths across the European continent, of which 1.9 million are in European Union countries [1]. Acute myocardial infarction (AMI) is the most common cause of mortality in patients with diabetes, as diabetic patients have twice the post-myocardial infarction mortality compared with nondiabetic patients [2].

Type 1 diabetes mellitus (T1DM) is characterized by destruction of $\beta$ cells (most often autoimmune) and an absolute insulin deficiency. The onset of T1DM is most common in childhood or young adults. Type 2 diabetes mellitus (T2DM) has the highest prevalence and is characterized by insulin resistance [3].

In experimental models of T1DM, insulin deficiency is obtained through various mechanisms, from surgical removal of the pancreas to chemical destruction of $\beta$-cells or other interventions that lead to the induction of autoimmune diabetes [4].

The most commonly used experimental model is the chemical one, in which pancreatic $\beta$ cells are destroyed by the administration of streptozotocin (STZ) or alloxan [4]. STZ is synthesized by Streptomyces achromogenes, which, after intraperitoneal or intravenous administration, enters the pancreatic $\beta$ cells through the Glut- 2 transporter and causes DNA alkylation [5]. Subsequent activation of poly(ADP-ribose) polymerase-1 (PARP-1) leads to depletion of nicotinamide adenine dinucleotide (NAD + ), a reduction in cellular ATP, and subsequent inhibition of insulin production. In addition, STZ is a source of free radicals that can also contribute to DNA damage and subsequent destruction of $\beta$ cells [4].

Isoproterenol (ISO) is a simple, easily reproducible with a low-mortality method to induce experimental AMI. Isoproterenol is a synthetic sympathomimetic catecholamine that, in experimental AMI, produces myocardial necrosis comparable to cardiomyocyte lesions in AMI in human tissue [6]. ISO acts non-selectively on $\beta 1$ and $\beta 2$ receptors and since $\beta 1$ receptors are predominantly present in the heart, their stimulation exerts positive chronotropic, dromotropic and inotropic effects [7]. Following isoproterenol administration, myocardial ischemia occurs in the context of an imbalance between oxygen demand due to increased cardiac activity and a reduced coronary blood supply [6]. ISO induces changes in cardiomyocyte metabolism and electrolyte content, decreases levels of high-energy phosphate deposits and increases oxidative stress, producing cardiotoxic effects and cardiomyocytes necrosis [8].

Curcumin (extracted from Curcuma longa) is a natural compound widely used in Asian cuisine, with therapeutic properties due to its antioxidant, anti-inflammatory, immunoregulatory, antimicrobial, antineoplastic, and antidiabetic effects [9]. It has been shown to have beneficial and versatile effects in various diseases such as diabetes, liver cirrhosis, local inflammation, neoplasms, cardiovascular disease, Alzheimer's disease, or migraine, but the molecular mechanisms underlying its effects are still under study [10]. Curcumin is hydrophobic, insoluble in water at neutral or acidic $\mathrm{pH}$, but soluble in vegetable oils, methanol, ethanol, dimethylsulfoxide and acetone [11]. One of the main problems facing the introduction of curcumin in clinical trials is its low bioavailability, which is due to poor absorption, accelerated metabolism and rapid digestive elimination. Multiple studies aimed to improve its pharmaceutical formula to increase its bioavailability. New pharmaceutical forms, capable of improving the bioavailability of curcumin molecules, are an essential step in enhancing this compound's therapeutic effects. However, there are still complex challenges in translating in vitro and in vivo studies to clinical trials [12]. 
Therefore, experimental studies are still of real use in better understanding the mechanisms associated with the beneficial effects of curcumin.

Curcumin nanoparticles and microparticles have been developed to improve the therapeutic properties of curcumin. The development of particles such as nano-liposomes, nano-gels, or nano-crystals has allowed a new approach to in vitro or in vivo experimental studies to increase curcumin's therapeutic efficacy in various conditions. The pharmaceutical formulations of nanocurcumin have been shown to maintain the molecule's pharmaceutical properties, with higher bioavailability than conventional curcumin [13].

The objectives of this study were to evaluate the cardio-protective, hepatoprotective and nephroprotective effects of curcumin nanoparticles (NC) pretreatment compared to conventional curcumin (CC) on experimental AMI in rats with T1DM.

\section{Materials and Methods}

\subsection{Ethics Statement}

All the experimental procedures followed the Helsinki Declaration on animal studies and were carried out according to the national and international guidelines for the care and use of animals.

\subsection{Animals}

The rats included in the study were obtained from the Animal Department of the Faculty of Medicine, Iuliu Haţieganu University of Medicine and Pharmacy Cluj-Napoca and were acclimatized in polypropylene cages, at $22-24^{\circ} \mathrm{C}, 12 \mathrm{~h} / 12 \mathrm{~h}$ light cycle/darkness. The animals had free access to water and food (standard pellets, Cantacuzino Institute, Bucharest, Romania).

\subsection{Chemicals and Reagents}

Isoproterenol hydrochloride (98\%), conventional curcumin, and streptozotocin were purchased from Sigma-Aldrich (St. Louis, MO, USA). Curcumin nanoparticles were purchased from CVI Pharma (Hanoi, Vietnam). In NC, the active compound, curcumin, is encapsulated in polymer-based nanoparticles ranging in size from $30 \mathrm{~nm}$ to $100 \mathrm{~nm}$. Waterbased, bio-compatible polymers were used to protect well-dispersed curcumin particles in water and to enhance gastrointestinal absorption (up to 95\%).

The nanoparticles of curcumin and curcumin were dissolved in peanut oil and administered orally by gavage. Peanut oil was used because it was observed that in this type of vegetable oil curcumin has an increased solubility without influencing the effects of curcumin [13].

\subsection{Diabetes Mellitus Induction}

Type 1 diabetes mellitus was induced by intraperitoneal (ip) administration of a single dose of freshly dissolved STZ (65 mg/Kg bw) in a $0.1 \mathrm{M}$ citrate buffer ( $\mathrm{pH} 4.5)$ [14]. Before the induction of T1DM, rats were given free access to water and food. In the first 48 hours after STZ administration, rats were given 5\% glucose to prevent hypoglycemic shock [14]. At 48 hours after STZ injection, blood samples were collected from the dorsal vein of the tail from all rats and blood glucose levels were measured using a glucometer (VivaChek Biotech (Hang-Zhou) Co., Ltd., Hangzhou, China). Rats with blood glucose greater than or equal to $200 \mathrm{mg} / \mathrm{dL}$ were considered to have T1DM [15]. All rats from T1DM groups had glycaemia $>200 \mathrm{mg} / \mathrm{dL} 48 \mathrm{~h}$ after STZ administration, as previously reported [16].

\subsection{Acute Myocardial Infarction Induction}

Acute myocardial infarction was induced with fresh ISO dissolved in saline $(0.09 \%)$ and injected subcutaneously at a dose of $45 \mathrm{mg} / \mathrm{Kg} \mathrm{bw}$ (bw_body weight) [17]. The successful induction of AMI in rats after ISO administration was proved by the elevation of CK, CK-MB, and LDH, as previously reported [16]. 


\subsection{Study Groups}

Fifty-six male Wistar-Bratislava rats, weighing between 200 and $250 \mathrm{~g}$ were randomly divided into eight groups of seven rats/group, as follows:

(1) Control group (C): Rats received only saline $(0.09 \%)$ throughout the whole experiment, administered by gavage. On day 7 , they were given an intraperitoneal citrate buffer, and on day 22 they were injected with saline $(0.09 \%)$ subcutaneously.

(2) Control group with acute myocardial infarction (AMI): Rats received only saline $(0.09 \%)$ throughout the whole experiment, administered by gavage. On day 7 they received an intraperitoneal citrate buffer, and on day 22 they were given ISO at a dose of $45 \mathrm{mg} / \mathrm{Kg}$ bw subcutaneously to induce AMI.

(3) Diabetic rats control group (T1DM): Rats received only saline $(0.09 \%)$ throughout the whole experiment, administered by gavage. On day 7 , they received $65 \mathrm{mg} / \mathrm{Kg}$ bw of intraperitoneal STZ for T1DM induction and on day 22 they were injected with saline $(0.09 \%)$ subcutaneously.

(4) Control group with diabetic rats and acute myocardial infarction (T1DM-AMI): Rats received only saline $(0.09 \%)$ throughout the whole experiment, administered by gavage. On day 7, they received $65 \mathrm{mg} / \mathrm{Kg}$ bw of intraperitoneal STZ to induce T1DM, and on day 22 they were injected with ISO at a dose of $45 \mathrm{mg} / \mathrm{Kg}$ bw subcutaneously to induce AMI.

(5) Group of diabetic rats pretreated with saline $(0.09 \%)$, treated with curcumin and induced AMI (S-T1DM-CC-AMI): Rats were pretreated with saline (0.09\%) for 7 days, administered by gavage. On the 7th day, they received $65 \mathrm{mg} / \mathrm{Kg}$ bw of intraperitoneal STZ for the induction of T1DM, in the next 15 days they were treated with curcumin solution in a dose of $200 \mathrm{mg} / \mathrm{Kg}$ bw administered by gavage, and on the 22nd day they were injected with ISO at a dose of $45 \mathrm{mg} / \mathrm{Kg}$ bw subcutaneously in order to induce AMI.

(6) Group of diabetic rats pretreated and treated with curcumin and induced AMI infarction (CC-T1DM-CC-AMI): Rats were pretreated with curcumin solution at a dose of $200 \mathrm{mg} / \mathrm{Kg}$ bw for 7 days administered by gavage. On day 7 , they received $65 \mathrm{mg} / \mathrm{Kg}$ bw of intraperitoneal STZ for T1DM induction, in the next 15 days they were treated with curcumin solution at a dose of $200 \mathrm{mg} / \mathrm{Kg}$ bw administered by gavage, and on day 22 they were injected with ISO at a dose of $45 \mathrm{mg} / \mathrm{Kg}$ bw subcutaneously in order to induce AMI.

(7) Group of diabetic rats pretreated with saline $(0.09 \%)$, treated with curcumin nanoparticles and induced AMI (S-T1DM-NC-AMI): Rats were pretreated with saline $(0.09 \%)$ for 7 days administered by gavage. On day 7 , they received $65 \mathrm{mg} / \mathrm{Kg}$ bw of intraperitoneal STZ for the induction of T1DM, in the next 15 days they were treated with a solution of curcumin nanoparticles at a dose of $200 \mathrm{mg} / \mathrm{Kg}$ bw administered by gavage, and on day 22 were injected with ISO at a dose of $45 \mathrm{mg} / \mathrm{Kg}$ bw subcutaneously in order to induce AMI.

(8) Group of diabetic rats pretreated and treated with curcumin nanoparticles and induced AMI (NC-T1DM-NC-AMI): Rats were pretreated with curcumin solution at a dose of $200 \mathrm{mg} / \mathrm{Kg}$ bw time for 7 days administered by gavage. On day 7, they received $65 \mathrm{mg} / \mathrm{Kg}$ bw of intraperitoneal STZ for inducing T1DM, in the next 15 days they were treated with a solution of curcumin nanoparticles at a dose of $200 \mathrm{mg} / \mathrm{Kg}$ bw administered by gavage, and on day 22 they were injected with ISO at a dose of $45 \mathrm{mg} / \mathrm{Kg}$ bw subcutaneously in order to induce AMI.

Figure 1 is a summary of the experimental groups involved in this study. 


\begin{tabular}{|c|c|c|c|c|c|c|c|c|}
\hline & C & T1DM & AMI & $\begin{array}{l}\text { T1DM- } \\
\text { AMI }\end{array}$ & $\begin{array}{l}\text { S-T1DM- } \\
\text { CC-AMI }\end{array}$ & $\begin{array}{l}\text { CC-T1DM- } \\
\text { CC-AMI }\end{array}$ & $\begin{array}{l}\text { S-T1DM- } \\
\text { NC-AMI }\end{array}$ & $\begin{array}{l}\text { NC-T1DM- } \\
\text { NC-AMI }\end{array}$ \\
\hline Days 1-7 & $\begin{array}{l}\text { Saline } \\
\text { (gavage) }\end{array}$ & $\begin{array}{l}\text { Saline } \\
\text { (gavage) }\end{array}$ & $\begin{array}{l}\text { Saline } \\
\text { (gavage) }\end{array}$ & $\begin{array}{l}\text { Saline } \\
\text { (gavage) }\end{array}$ & $\begin{array}{l}\text { Saline } \\
\text { (gavage) }\end{array}$ & $\begin{array}{l}\text { Curcumin } \\
\text { (gavage) }\end{array}$ & $\begin{array}{l}\text { Saline } \\
\text { (gavage) }\end{array}$ & $\begin{array}{c}\text { Curcumin } \\
\text { nanoparticles } \\
\text { (gavage) }\end{array}$ \\
\hline Day 7 & $\begin{array}{l}\text { CB } \\
\text { (i.p.) }\end{array}$ & $\begin{array}{l}\text { STZ } \\
\text { (ip.) }\end{array}$ & $\begin{array}{l}\text { CB } \\
\text { (i.p.) }\end{array}$ & $\begin{array}{l}\text { STZ } \\
\text { (ip.) }\end{array}$ & $\begin{array}{l}\text { STZ } \\
\text { (.ip.) }\end{array}$ & $\begin{array}{l}\text { STZ } \\
\text { (ip.) }\end{array}$ & $\begin{array}{l}\text { STZ } \\
\text { (.ip.) }\end{array}$ & $\begin{array}{l}\text { STZ } \\
\text { (.ip.) }\end{array}$ \\
\hline Days 8-22 & $\begin{array}{l}\text { Saline } \\
\text { (gavage) }\end{array}$ & $\begin{array}{l}\text { Saline } \\
\text { (gavage) }\end{array}$ & $\begin{array}{l}\text { Saline } \\
\text { (gavage) }\end{array}$ & $\begin{array}{l}\text { Saline } \\
\text { (gavage) }\end{array}$ & $\begin{array}{c}\text { Curcumin } \\
\text { (gavage) }\end{array}$ & $\begin{array}{l}\text { Curcumin } \\
\text { (gavage) }\end{array}$ & $\begin{array}{c}\text { Curcumin } \\
\text { nanoparticles } \\
\text { (gavage) }\end{array}$ & $\begin{array}{c}\text { Curcumin } \\
\text { nanoparticles } \\
\text { (gavage) }\end{array}$ \\
\hline Day 22 & $\begin{array}{l}\text { Saline } \\
\text { (s.c.) }\end{array}$ & $\begin{array}{r}\text { ISO } \\
\text { (s.c.) }\end{array}$ & $\begin{array}{l}\text { Saline } \\
\text { (s.c.) }\end{array}$ & $\begin{array}{r}\text { ISO } \\
\text { (s.c.) }\end{array}$ & $\begin{array}{l}\text { ISO } \\
\text { (s.c.) }\end{array}$ & $\begin{array}{l}\text { ISO } \\
\text { (s.c.) }\end{array}$ & $\begin{array}{l}\text { ISO } \\
\text { (s.c.) }\end{array}$ & $\begin{array}{l}\text { ISO } \\
\text { (s.c.) }\end{array}$ \\
\hline
\end{tabular}

Figure 1. Flow chart demonstrating the experimental study groups. Abbreviations: C—control; AMI-acute myocardial infarction; T1DM-type 1 diabetes mellitus; S—saline (0.09\%); CC—conventional curcumin; NC—solution of curcumin nanoparticles; CB—citrate buffer; i.p.—intraperitoneal; STZ—streptozotocin; s.c.—subcutaneous; ISO—isoproterenol.

\subsection{Electrocardiographic Monitoring}

Electrocardiographic (ECG) monitoring was performed at $24 \mathrm{~h}$ after ISO administration, using the Biopac MP36 system (Goleta, CA, USA). Rats were anesthetized by intraperitoneal administration of ketamine $(26 \mathrm{mg} / \mathrm{Kg} \mathrm{bw})$ and xylazine $(2.6 \mathrm{mg} / \mathrm{Kg} \mathrm{bw})$.

Fifteen minutes after induction of anesthesia, electrodes were attached to the paws of each rat and the ECGs were recorded in the DII lead. The RR interval (the time elapsed between two successive R-waves of the QRS signal on the electrocardiogram) (ms), QT interval (the time from the beginning of the QRS complex to the end of the T wave) (ms), PR segment (the isoelectric segment between the end of the P wave and the start of the QRS complex) (ms), QRS complex duration (ms), ST-segment modifications (mV), and R-wave amplitude $(\mathrm{mV})$ were calculated from ECG recordings using Biopac Student Lab 3.7.7 software (Goleta, CA, USA).

Heart rate (beats $/ \mathrm{min}$ ) was calculated according to the RR interval using the following formula: $\mathrm{HR}=60,000 / \mathrm{RR}$. The corrected QT interval (QTc) (ms) was calculated according to the modified Bazett formula: $\mathrm{QTc}=\mathrm{QT} / \sqrt{ }(\mathrm{RR} / 150)[18]$.

\subsection{Biochemical Analysis}

For biochemical analysis, blood samples were collected from the retro-orbital plexuses of each rat 24 hours after ISO administration, right after the ECG monitoring was done.

Blood glucose, aspartate transaminase (AST), alanine transaminase (ALT), creatinine and urea levels were measured using the Jasco V-530 UV/Vis spectrophotometer (JASCO International Co., Ltd., Tokyo, Japan) using commercial kits available from Spinreact, Girona, Spain.

Serum C-peptide values and serum levels of matrix metalloproteinase 2 (MMP-2) and matrix metalloproteinase 9 (MMP-9) were determined by ELISA (Stat Fax 303 Plus Microstrip Reader, Minneapolis, MN, USA) using commercially available kits.

\subsection{Histopathological Examination}

After blood samples were taken, rats were sacrificed by an overdose of anesthetics. Afterward, their hearts were excised, washed immediately with saline, and then fixed in $10 \%$ formalin. After being embedded in paraffin, they were sectioned at $3 \mu \mathrm{m}$, stained with hematoxylin and eosin (H\&E) and examined under a light microscope.

\subsection{Statistical Analysis}

The measured parameters were expressed as mean and standard deviation. In the figures, the distribution of the investigated parameters was represented as individual 
values (circles) and median (as line) as recommended by Weissgerber et al. [19]. Differences between groups were assessed by the Mann-Whitney test. The level of statistical significance was set at $<0.05$.

\section{Results}

No rat died during the follow-up; therefore, statistical analysis was performed on all seven rats in each group.

\subsection{Serum Levels of Glucose and C-Peptide}

Administration of STZ led to a significant increase in plasma glucose and a significant decrease in plasma C-peptide levels in diabetic rats (Figure 2). Rats with AMI showed a slight increase in serum glucose after administration of ISO, and rats with T1DM and AMI presented the highest values (Figure 2a). Rats from groups with T1DM showed a lower serum level of C-peptide. Rats from the AMI group that received only ISO presented peptide $C$ values comparable to the control group (Figure $2 b$ ).

(a)

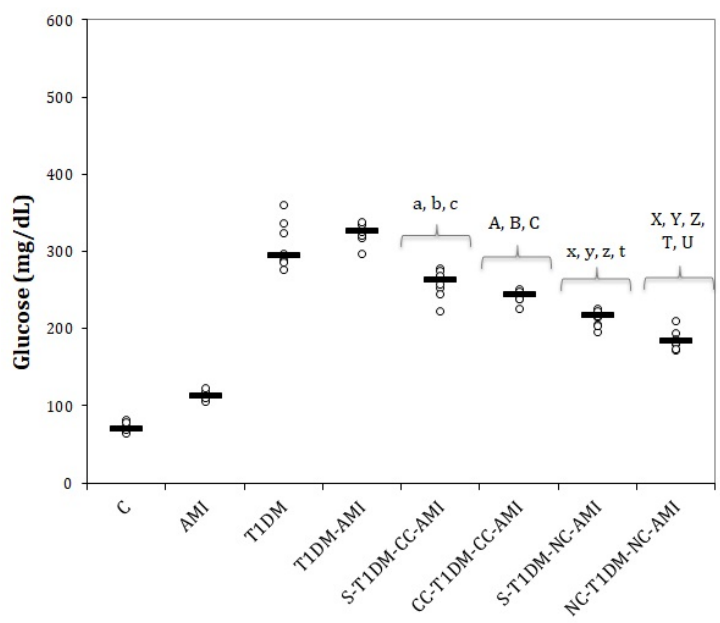

(b)

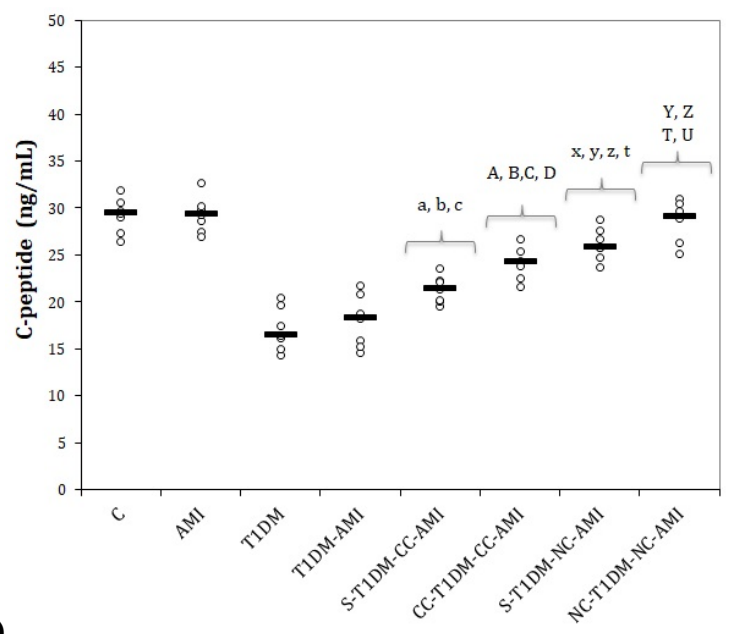

Figure 2. Serum blood glucose and C-peptide levels: (a) glucose; (b) C-peptide. C-control; AMI-acute myocardial infarction; T1DM-type 1 diabetes mellitus; S-saline (0.09\%); CC—conventional curcumin solution $(200 \mathrm{mg} / \mathrm{Kg} \mathrm{bw})$; NC—solution of curcumin nanoparticles $(200 \mathrm{mg} / \mathrm{Kg} \mathrm{bw})$. The letters correspond to $p$ values <0.05: (a) S-T1DM-CCAMI compared to AMI; (b) S-T1DM-CC-AMI compared to T1DM; (c) S-T1DM-CC-AMI compared to T1DM-AMI; (A) CC-T1DM-CC-AMI compared to AMI; (B) CC-T1DM-CC-AMI compared to T1DM; (C) CC-T1DM-CC-AMI compared to T1DM-AMI; (D) CC-T1DM-CC-AMI compared to S-T1DM-CC-AMI; (x) S-T1DM-NP-AMI compared to AMI; (y) ST1DM-NP-AMI compared to T1DM; (z) S-T1DM-NP-AMI compared to T1DM-AMI; (t) S-T1DM-NP-AMI compared to S-T1DM-CC-AMI; (X) NP-T1DM-NP-AMI compared to AMI; (Y) NP-T1DM-NP-AMI compared to T1DM; (Z) NP-T1DMNP-AMI compared to T1DM-AMI; (T) NP-T1DM-NP-AMI compared to CC-T1DM-CC-AMI; (U) NP-T1DM-NP-AMI compared to S-T1DM-NP-AMI.

Both groups of rats that received CC had lower serum glucose levels than the T1DM and T1DM-AMI groups (Figure 2a, $p \leq 0.0022$ ). No statistically significant differences were observed when comparing the two groups that received CC $(p>0.05$, Figure $2 a)$. The groups that received curcumin nanoparticles had the lowest serum glucose levels compared to the groups that received conventional curcumin (Figure $2 a, p \leq 0.004$ ). The best results were obtained for the group pretreated with NC before T1DM induction (Figure 2a).

The groups that received CC and NC had higher serum levels of C-peptide than the T1DM or T1DM-AMI groups (Figure 2b, $p \leq 0.0298$ ). Conventional curcumin adminsitration before T1DM induction provided an increase in C-peptide levels compared to the group pretreated with saline and CC after T1DM induction (Figure $2 b, p=0.0106$ ). The same results were observed for the groups that received NC $(p=0.0409$, Figure $2 b)$. The 
best results for C-peptide were obtained from the groups that received only NC from the beginning of the experiment $(p \leq 0.0409$, Figure $2 b)$.

\subsection{Electrocardiogram Monitoring and Histological Changes of the Heart}

Figure 3 shows the ECG changes characteristic for all groups included in the study. The results of the interpretations of the ECGs are presented in Table 1.

a)

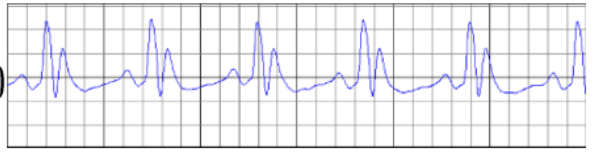

b)

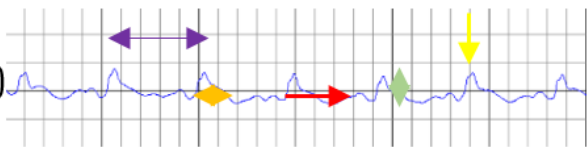

c)

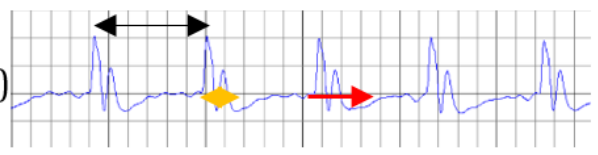

d)

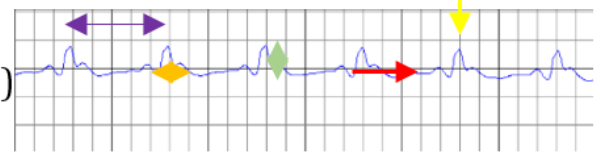

f)

g)

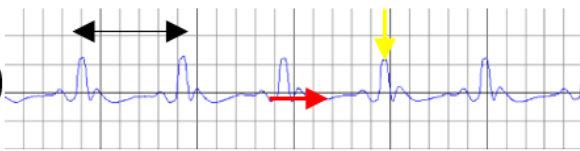

e)
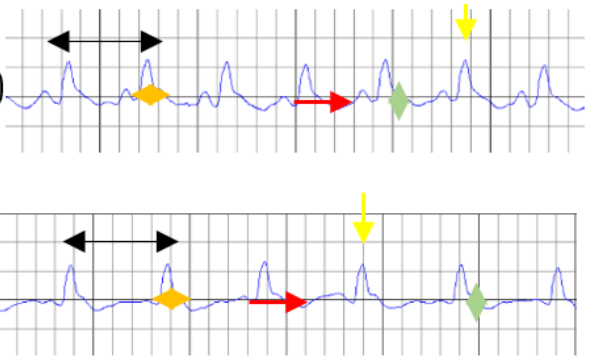

h)

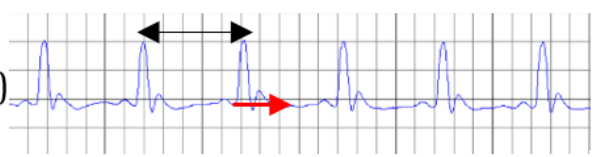

Figure 3. ECG changes characteristic of each group. (a) C, (b) AMI, (c) T1DM, (d) T1DM-AMI, (e) ST1DM-CC-AMI, (f) CC-T1DM-CC-AMI, (g) S-T1DM-NC-AMI, (h) NC-T1DM-NC-AMI. Increased RR interval (black arrow), reduced RR interval (purple arrow), lengthening of the QRS complex (orange arrow), increased QT interval (red arrow), ST-segment elevation (green arrow), reduced amplitude of the $\mathrm{R}$ wave (yellow arrow). C—control; AMI—acute myocardial infarction; T1DM-type 1 diabetes mellitus; S-saline (0.09\%); CC—conventional curcumin solution $(200 \mathrm{mg} / \mathrm{Kg} \mathrm{bw})$; NC—solution of curcumin nanoparticles $(200 \mathrm{mg} / \mathrm{Kg}$ bw).

Table 1. ECG interpretation for each group.

\begin{tabular}{lcccccccc}
\hline \multicolumn{1}{c}{ Abbreviation } & RR(ms) & HR(b/min) & PR(ms) & QRS(ms) & QT(ms) & QTc(ms) & R(mV) & ST(mV) \\
\hline C & $209(7.0)$ & $287(9.6)$ & $44(2.1)$ & $35(2.2)$ & $75(4.4)$ & $64(3.7)$ & $3(0.11)$ & $0.00(0.00)$ \\
AMI & $180(3.1)$ & $333(5.7)$ & $45(2.2)$ & $53(2.3)$ & $103(3.6)$ & $94(3.0)$ & $1.3(0.10)$ & $0.09(0.01)$ \\
T1DM & $239(8.7)$ & $252(9.4)$ & $43(1.7)$ & $42(1.3)$ & $85(3.6)$ & $68(2.4)$ & $2.1(0.13)$ & $0.00(0.00)$ \\
T1DM-AMI & $191(3.0)$ & $314(5.0)$ & $44(2.6)$ & $57(2.0)$ & $113(3.0)$ & $100(2.7)$ & $1.2(0.08)$ & $0.10(0.02)$ \\
S-T1DM-CC-AMI & $223(3.6)$ & $269(4.3)$ & $43(1.5)$ & $42(2.2)$ & $99(2.5)$ & $81(1.6)$ & $1.2(0.13)$ & $0.08(0.01)$ \\
CC-T1DM-CC-AMI & $226(6.6)$ & $266(7.7)$ & $43(1.5)$ & $40(1.3)$ & $94(2.9)$ & $76(3.1)$ & $1.4(0.13)$ & $0.08(0.02)$ \\
S-T1DM-NC-AMI & $249(6.1)$ & $241(5.8)$ & $44(1.7)$ & $37(1.7)$ & $88(1.7)$ & $68(1.2)$ & $1.7(0.17)$ & $0.05(0.01)$ \\
NC-T1DM-NC-AMI & $250(3.4)$ & $240(3.4)$ & $44(1.4)$ & $37(1.6)$ & $87(2.7)$ & $67(2.1)$ & $2.1(0.17)$ & $0.02(0.01)$ \\
\hline
\end{tabular}

The values in the table represent the mean and standard deviation (in round brackets): HR-heart rate; C-control; AMI—acute myocardial infarction; T1DM-type 1 diabetes mellitus; S—saline (0.09\%); CC—conventional curcumin solution (200 mg/Kg bw); NC—solution of curcumin nanoparticles $(200 \mathrm{mg} / \mathrm{Kg} \mathrm{bw})$.

Administration of ISO induced important ECG changes, such as reduced RR intervals, increased HR (heart rate) and QT and QTc intervals, QRS complex prolongation, STsegment elevation, and reduced R-wave amplitude (Figure 3b, Table 1). These changes are characteristic of ISO-induced AMI. The administration of STZ caused a lengthening of the RR interval and a decrease in HR, but also a prolongation of the QRS complex. Both ISO and STZ did not affect the PR segment (Figure 3, Table 1).

Conventional curcumin and NC increased the RR interval and decreased HR in all groups (Figure 3e-h, Table 1), with significantly better NC than CC (Table 1, $p=0.0021$ ). 
$\mathrm{NC}$ was more effective than CC in preventing elongation of the QRS complex (Figure $3 \mathrm{e}-\mathrm{h}$, Table $1, p \leq 0.0057)$, without statistically significant differences between the two groups that received NC $(p>0.05)$.

Curcumin nanoparticles more effectively prevented the prolongation of QT and QTc intervals after AMI induction, compared to conventional curcumin (Figure $3 \mathrm{e}-\mathrm{h}$, Table 1 , $p \leq 0.0026)$, without statistically significant differences between the two groups that had received $\mathrm{NC}(p>0.05)$.

The administration of NC most effectively prevented the R-wave amplitude reduction prior to T1DM induction (Figure 3, Table 1, $p \leq 0.0048$ )

Curcumin nanoparticles effectively reduced ST-segment elevation (Figure $3 g-h$, Table 1 , $p \leq 0.0021)$. The best effect for reducing ST-segment changes was obtained for NC administered before T1DM induction (Figure 3h, Table 1, $p \leq 0.0066$ ).

Histopathological examinations revealed a normal architecture of myocardial tissue of the rats from the control group (Figure 4a), multifocal necrosis associated with diffuse infiltration with leukocytes in rats in the AMI group (Figure 4b). Rats from the T1DM group presented only blood stasis (Figure 4c). Multifocal necrosis associated with diffuse infiltration with leukocytes and stasis was observed in the T1DM-AMI group (Figure 4d). Rats who received conventional curcumin presented multifocal necrosis with inflammatory infiltration of leukocytes (Figure 4e,f), while rats from the groups that received curcumin nanoparticles presented localized subendocardial necrosis with infiltration of leukocytes (Figure 4g,h).

(a)

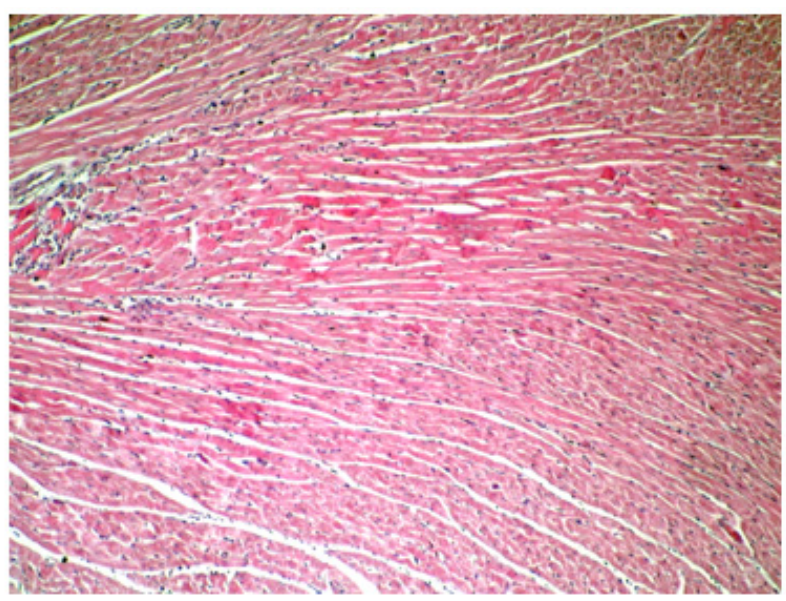

(b)
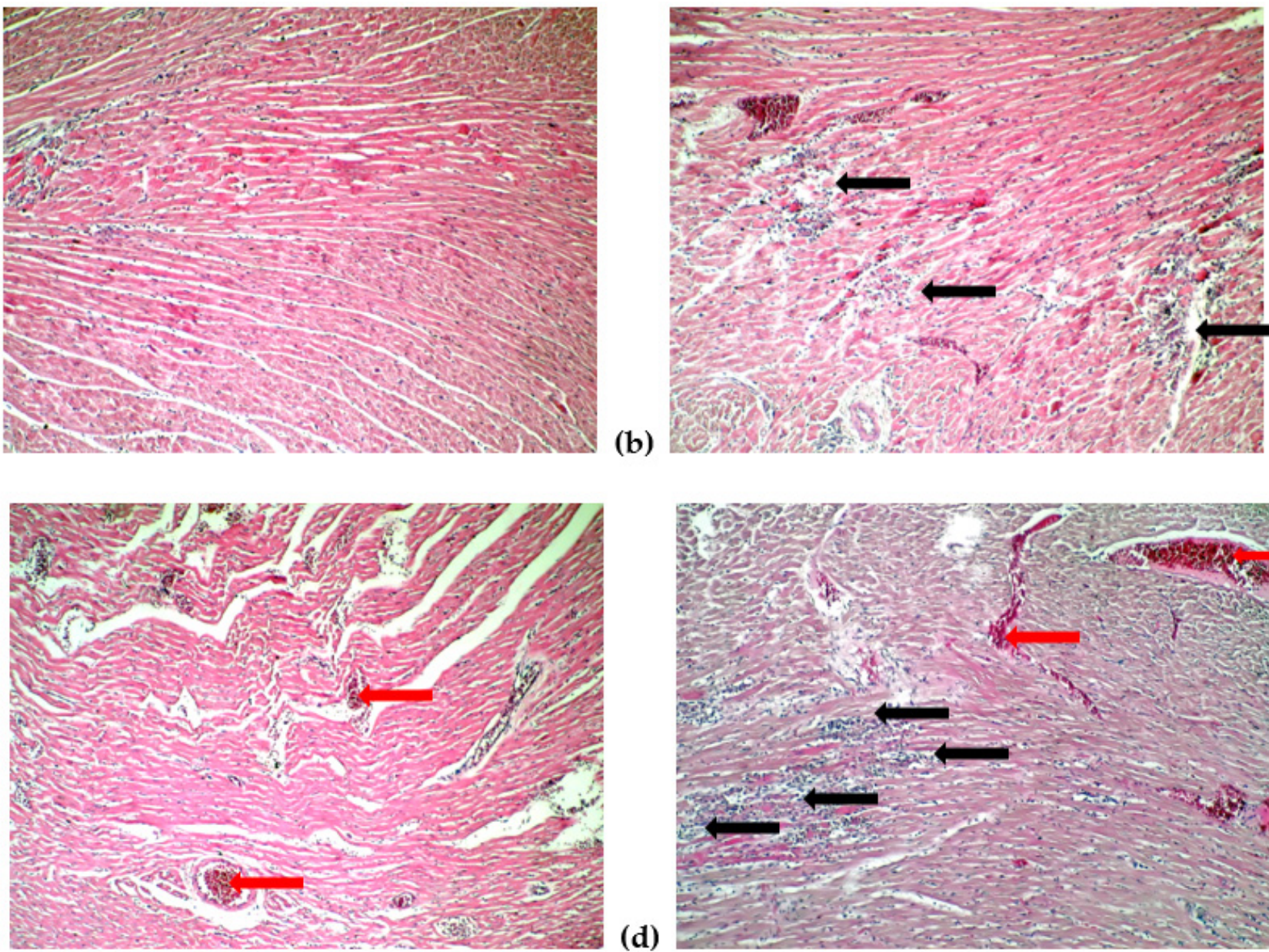

(d)

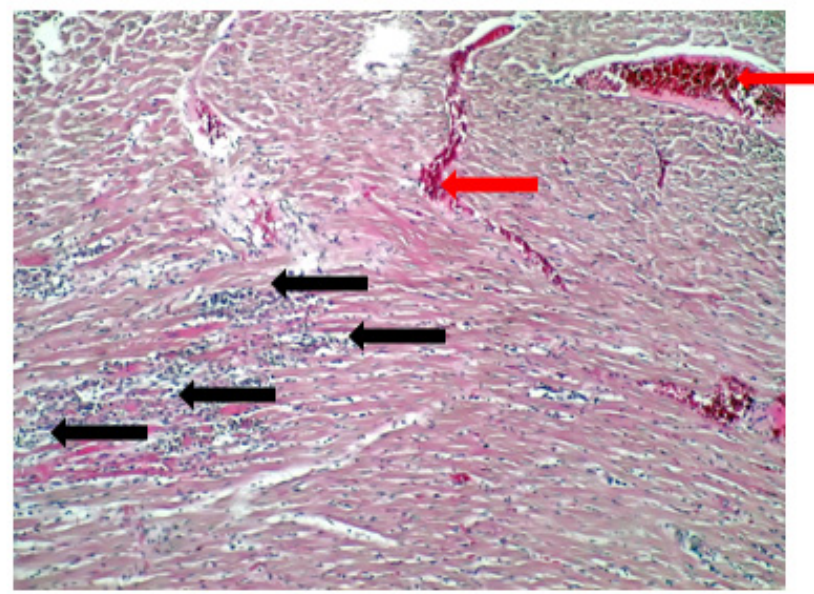

Figure 4. Cont. 
(e)

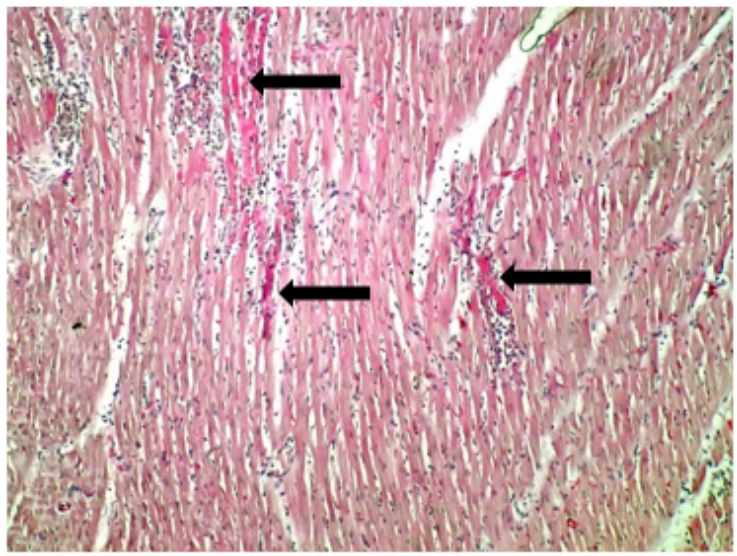

(f)

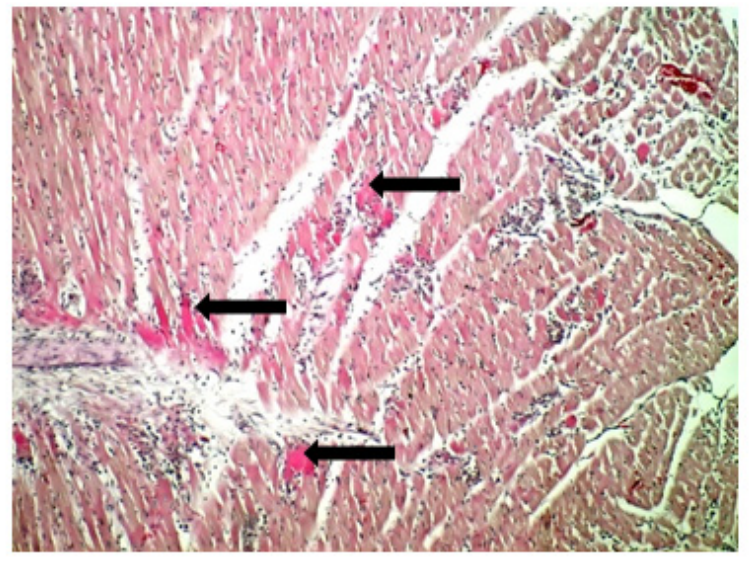

(g)

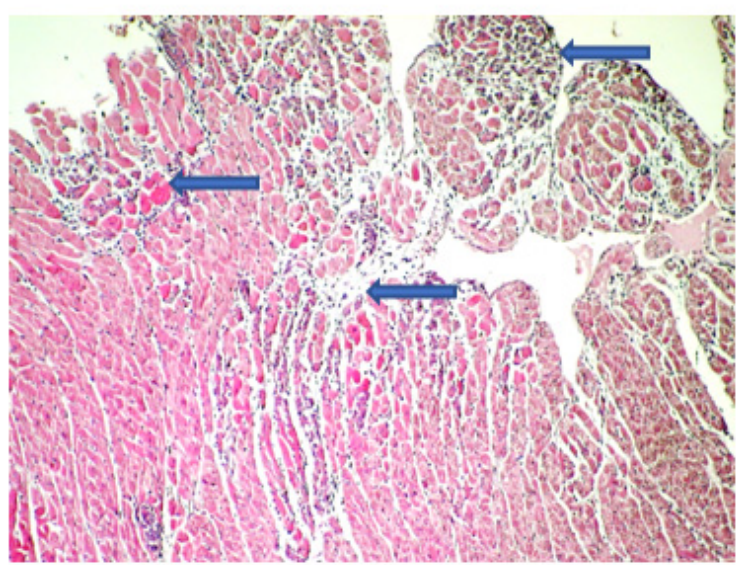

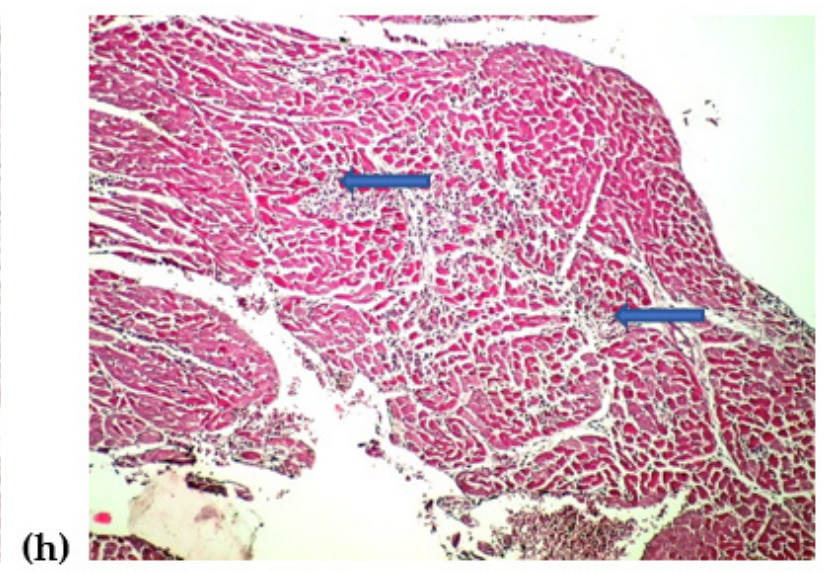

Figure 4. Histopathological examinations of the heart tissue. (a) C (normal architecture of the myocardium), (b) AMI (multifocal necrosis associated with diffuse infiltration with leukocytes (black arrow)), (c) T1DM (blood stasis with well recognizable integral erythrocytes in a congested blood vessel (red arrow)), (d) T1DM-AMI (multifocal necrosis associated with diffuse infiltration with leukocytes (black arrow), and blood stasis (red arrow)), (e) S-T1DM-CC-AMI (multifocal necrosis with inflammatory infiltration of leukocytes), (f) CC-T1DM-CC-AMI (multifocal necrosis with inflammatory infiltration of leukocytes), (g) S-T1DM-NC-AMI (subendocardial necrosis with inflammatory infiltration of leukocytes (blue arrows)), (h) NC-T1DM-NC-AMI (subendocardial necrosis with inflammatory infiltration of leukocytes (blue arrows)).

\subsection{Serum Levels of Liver Function Parameters and Liver Histopathological Changes}

Rats with T1DM, and also those with AMI, presented elevated levels of hepatic cytolysis enzymes, most high levels were seen in diabetic rats with AMI (Figure 5). Curcumin administration prevented elevation of AST and ALT compared to diabetic rats with AMI (Figure 5, $p \leq 0.022$ ). Curcumin nanoparticle administration reduced AST and ALT serum levels better than conventional curcumin, with lower levels for rats who received the active compound before T1DM induction (Figure 5, $p \leq 0.0152$ ).

Histopathologic examination of the liver showed normal architecture of the liver in the control group (Figure 6a). Rats with AMI presented liver stasis (Figure 6b). Rats who received STZ associated multifocal liver micronecrosis (Figure 6c), while the group with T1DM and AMI presented lobular micronecrosis and blood stasis (Figure 6d). Curcumin administration reduced liver injury to focal necrosis (Figure $6 \mathrm{e}, \mathrm{f}$ ). Rats who received curcumin nanoparticles administered after T1DM induction presented liver stasis (Figure 6g), while rats who received curcumin nanoparticles from the beginning of the experiment had a normal aspect of the liver (Figure $6 \mathrm{~h}$ ). 
(a)

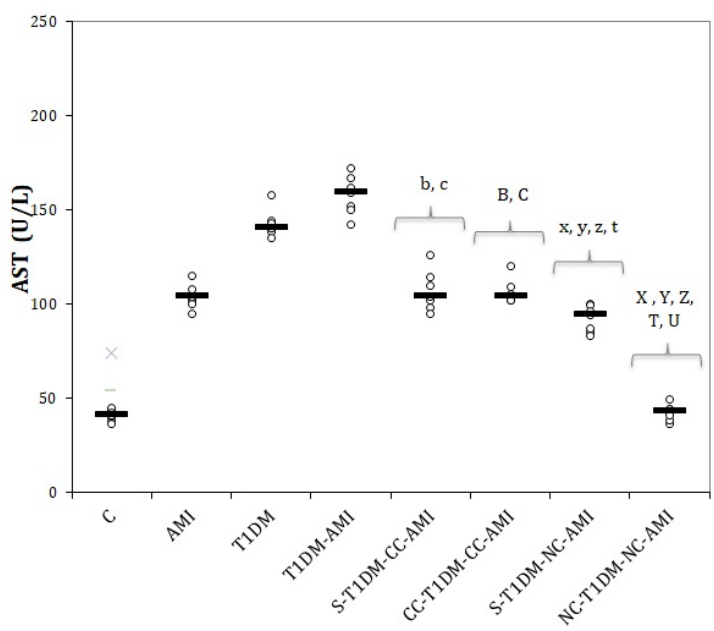

(b)

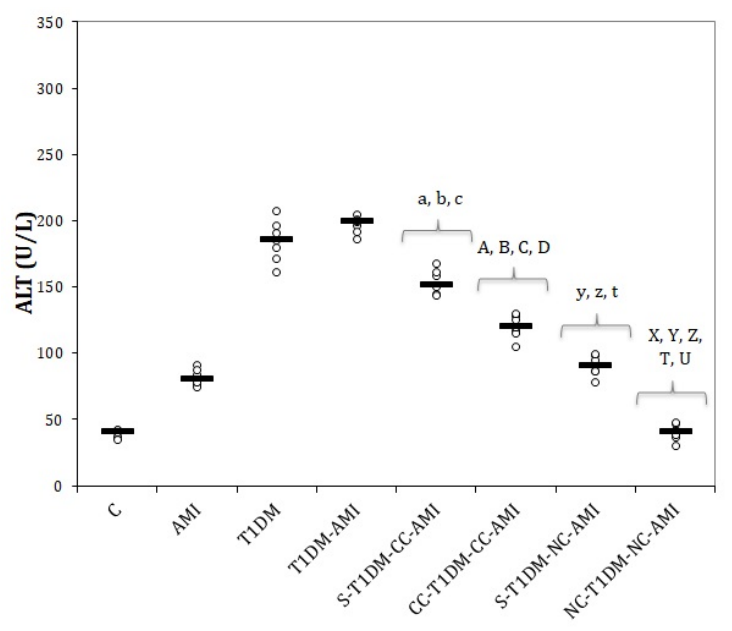

Figure 5. Serum levels of liver function parameters: (a) Aspartate transaminase (AST); (b) Alanine transaminase (ALT). C-control; AMI-acute myocardial infarction; T1DM-type 1 diabetes mellitus; S—saline (0.09\%); CC-conventional curcumin solution (200 mg/Kg bw); NC—solution of curcumin nanoparticles ( $200 \mathrm{mg} / \mathrm{Kg} \mathrm{bw})$. The letters correspond to $p$ values <0.05: (a) S-T1DM-CC-AMI compared to AMI; (b) S-T1DM-CC-AMI compared to T1DM; (c) S-T1DM-CC-AMI compared to T1DM-AMI; (A) CC-T1DM-CC-AMI compared to AMI; (B) CC-T1DM-CC-AMI compared to T1DM; (C) CC-T1DM-CC-AMI compared to T1DM-AMI; (D) CC-T1DM-CC-AMI compared to S-T1DM-CC-AMI; (x) S-T1DM-NP-AMI compared to AMI; (y) S-T1DM-NP-AMI compared to T1DM; (z) S-T1DM-NP-AMI compared to T1DM-AMI; (t) S-T1DMNP-AMI compared to S-T1DM-CC-AMI; (X) NP-T1DM-NP-AMI compared to AMI; (Y) NP-T1DM-NP-AMI compared to T1DM; (Z) NP-T1DM-NP-AMI compared to T1DM-AMI; (T) NP-T1DM-NP-AMI compared to CC-T1DM-CC-AMI; (U) NP-T1DM-NP-AMI compared to S-T1DM-NP-AMI. (a)

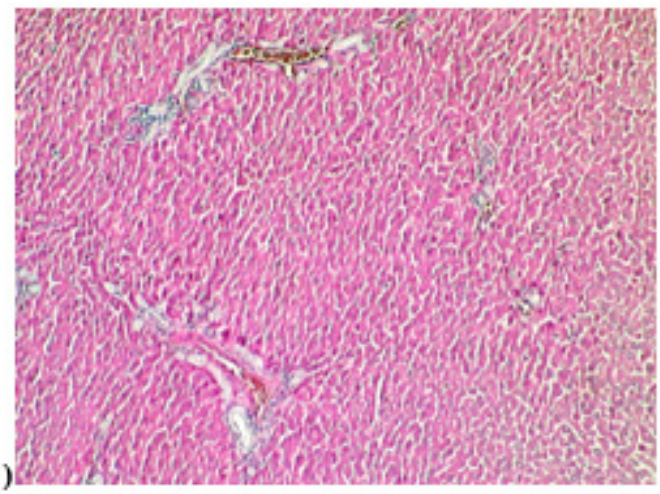

(b)

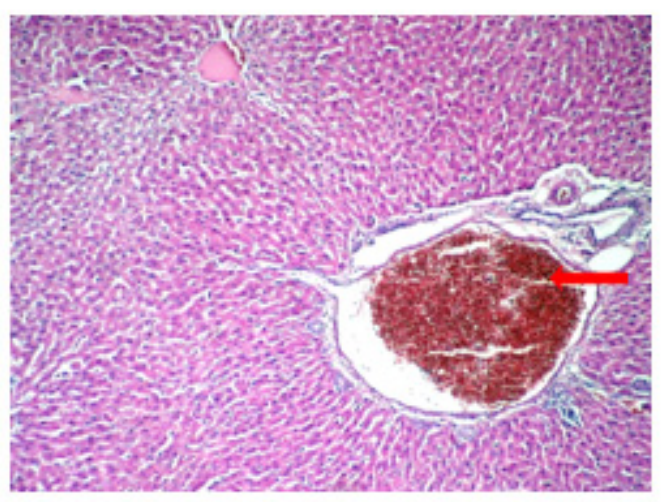

(c)

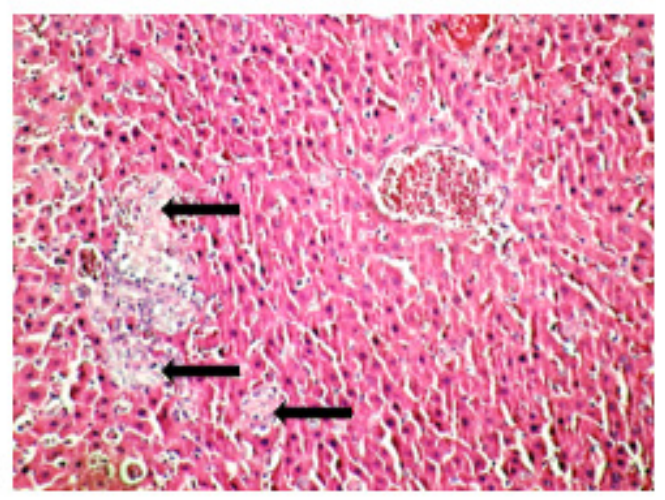

(d)

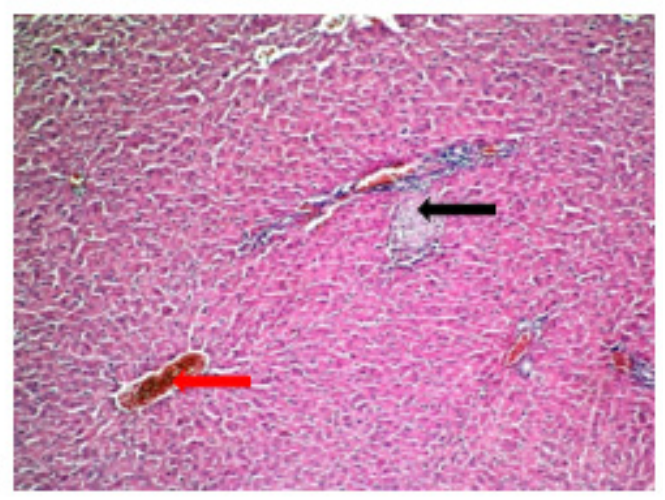

Figure 6. Cont. 

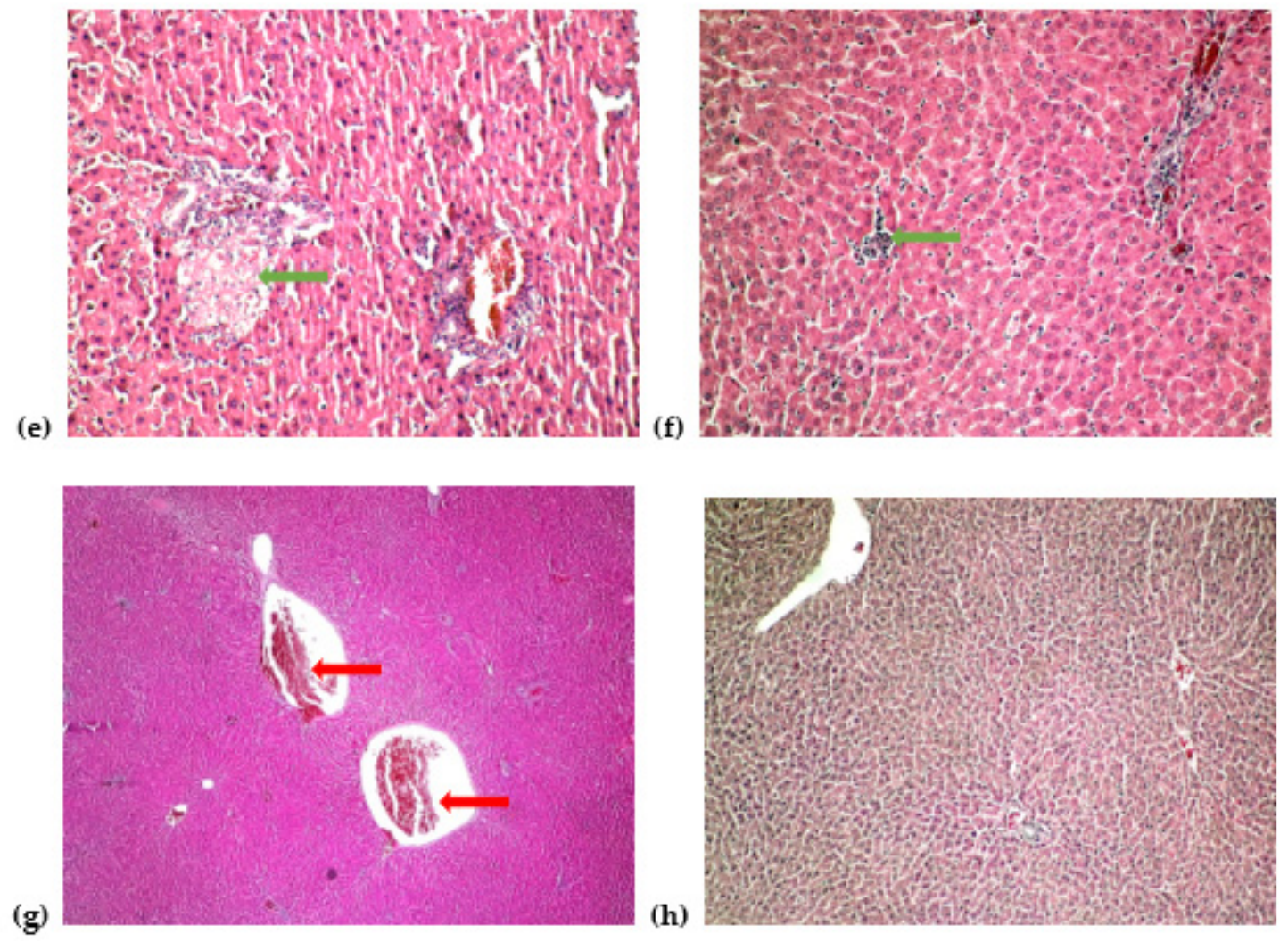

Figure 6. Histopathological examinations of the liver tissue. (a) C (normal architecture of the liver), (b) AMI (blood stasis with well recognizable integral erythrocytes in a congested blood vessel (red arrow)), (c) T1DM (multifocal micronecrosis (black arrow)), (d) T1DM-AMI (lobular micronecrosis (black arrow) and blood stasis (red arrow)), (e) S-T1DM-CC-AMI (focal necrosis (green arrow)), (f) CC-T1DM-CC-AMI (focal necrosis (green arrow)), (g) S-T1DM-NC-AMI (blood stasis with well recognizable integral erythrocytes in a congested blood vessel (red arrow)), (h) NC-T1DM-NC-AMI (normal architecture of the liver).

\subsection{Serum Levels of Kidney Function Parameters and Kidney Histopathological Changes}

ISO administration did not influence the creatinine levels (Figure 7a) but caused a significant increase in urea levels (Figure 7b). Rats from the group who received only STZ showed an increase in creatinine and urea serum levels (Figure 7). Rats with T1DM and associated AMI presented the most elevated serum levels of kidney function parameters (Figure 7).

Curcumin administered at the beginning of the experiment better prevented elevation of creatinine compared to rats from the group that received curcumin only after T1DM induction (Figure 7a, $p=0,0172$ ), while no differences were observed between these two groups for urea serum levels (Figure $7 \mathrm{~b}, p>0.05$ ).

Curcumin nanoparticles offered better results in preventing elevation of these parameters when compared to conventional curcumin (Figure $7, p \leq 0.0021$ ), but no statistical differences were found between the two groups that received curcumin nanoparticles for neither creatinine nor for urea (Figure $7, p \geq 0.05$ ).

Histological examination of the kidneys visualized a normal architecture of the kidneys in the control group (Figure 8a). Rats with AMI presented blood stasis (Figure 8b). In the group with T1DM and in the group with T1DM and AMI the rats had a glomerular collapse and blood stasis (Figure 8c,d). Curcumin administration reduced kidney histological damage to stasis (Figure 8e,f). Similar results were observed in the group that received curcumin nanoparticles after STZ administration (Figure 8g), while the group that received curcumin nanoparticles before STZ administration had a normal aspect of the kidney (Figure 8h). 


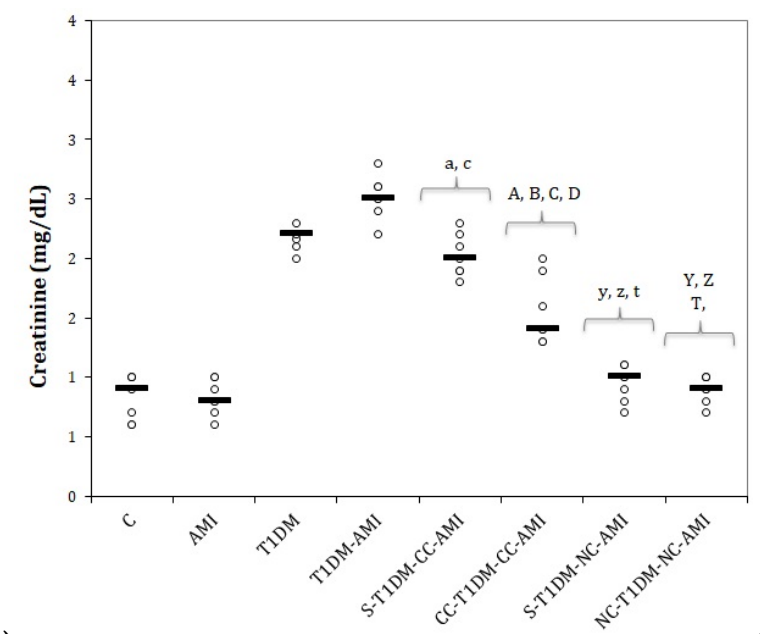

(a)

Figure 7. Serum levels of kidney function parameters: (a) Creatinine; (b) Urea. C-control; AMI-acute myocardial infarction; T1DM-type 1 diabetes mellitus; S—saline (0.09\%); CC—conventional curcumin solution (200 mg/Kg bw); NC—solution of curcumin nanoparticles $(200 \mathrm{mg} / \mathrm{Kg} \mathrm{bw})$. The letters correspond to $p$ values <0.05: (a) S-T1DM-CC-AMI compared to AMI; (b) S-T1DM-CC-AMI compared to T1DM; (c) S-T1DM-CC-AMI compared to T1DM-AMI; (A) CC-T1DMCC-AMI compared to AMI; (B) CC-T1DM-CC-AMI compared to T1DM; (C) CC-T1DM-CC-AMI compared to T1DM-AMI; (D) CC-T1DM-CC-AMI compared to S-T1DM-CC-AMI; (x) S-T1DM-NP-AMI compared to AMI; (y) S-T1DM-NP-AMI compared to T1DM; (z) S-T1DM-NP-AMI compared to T1DM-AMI; (t) S-T1DM-NP-AMI compared to S-T1DM-CC-AMI; (Y) NP-T1DM-NP-AMI compared to T1DM; (Z) NP-T1DM-NP-AMI compared to T1DM-AMI; (T) NP-T1DM-NP-AMI compared to CC-T1DM-CC-AMI.

(a)
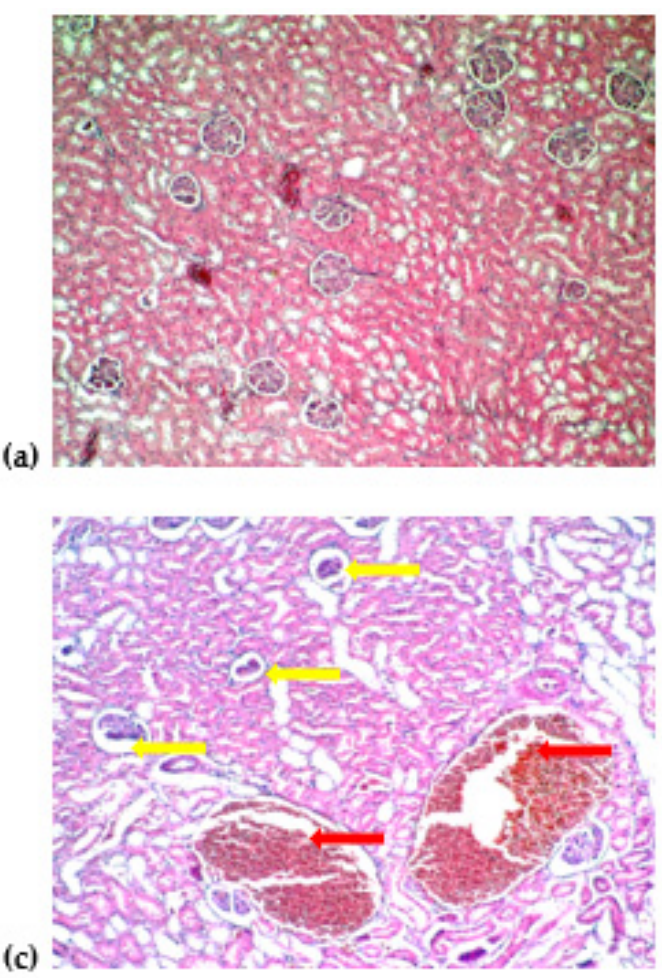

(b)

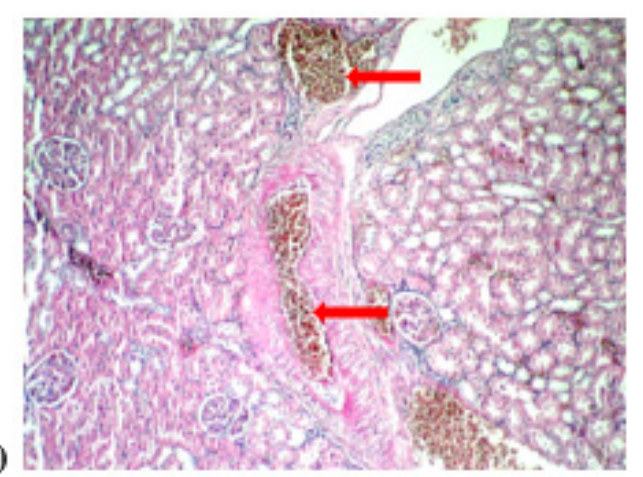

(d)

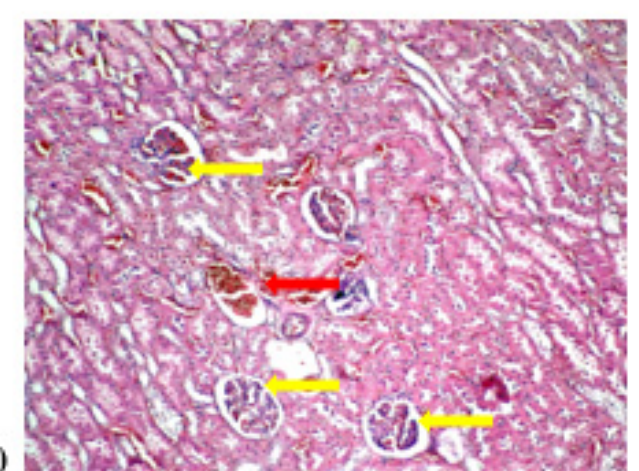

Figure 8. Cont. 
(e)

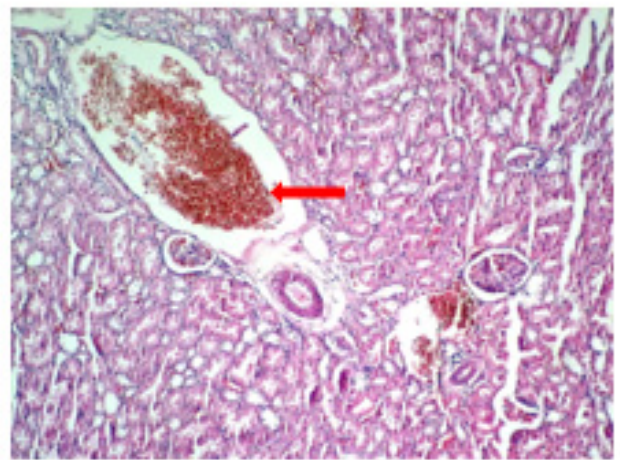

(f)
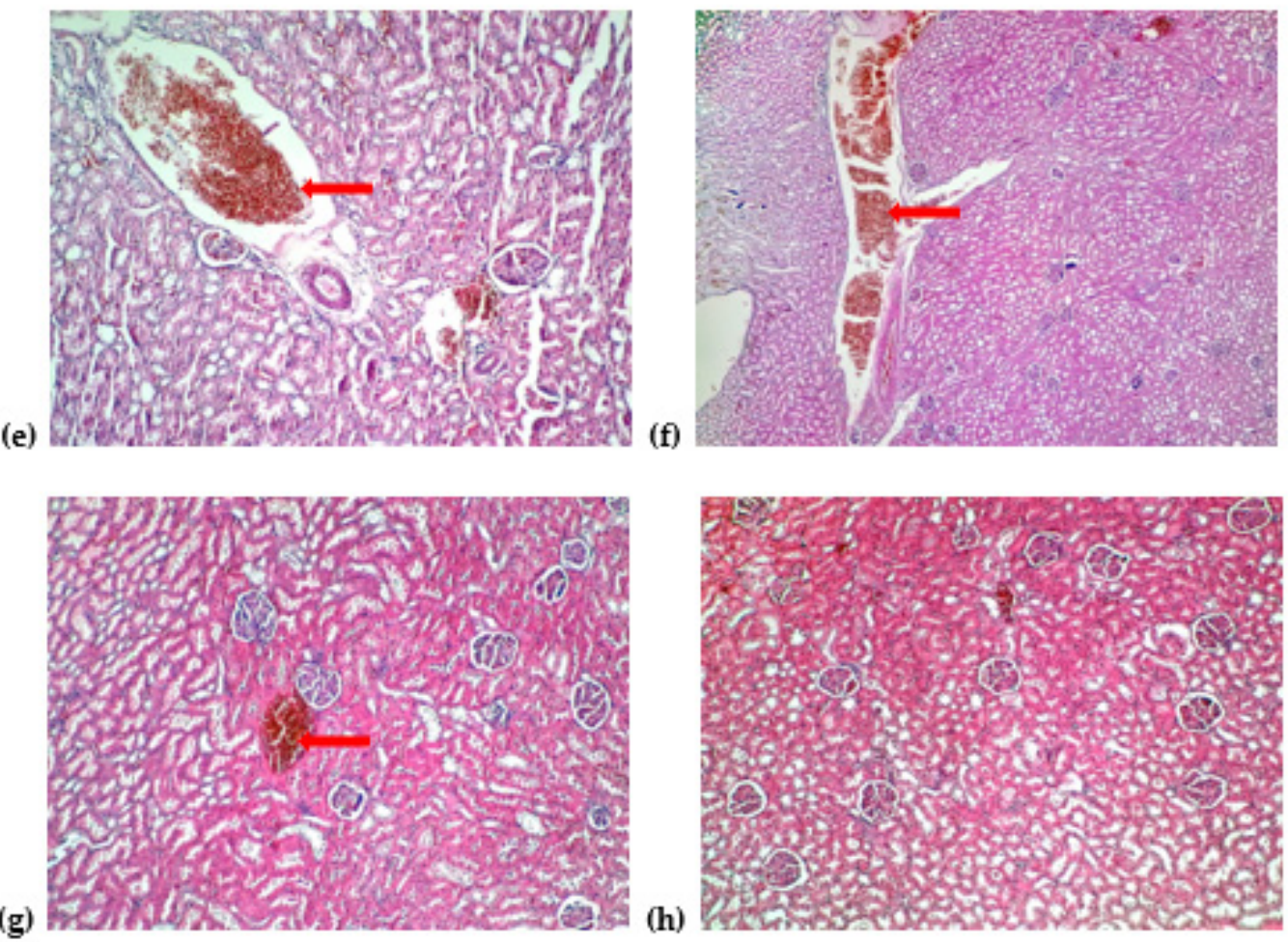

(h)

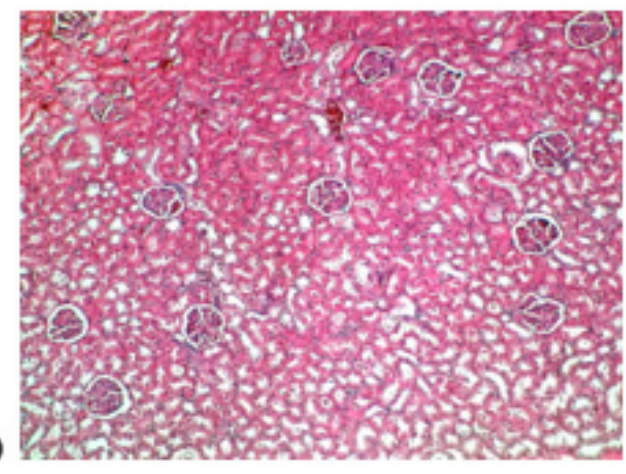

Figure 8. Histopathological examinations of the kidney tissue. (a) C (normal architecture of the kidneys), (b) AMI (blood stasis with well recognizable integral erythrocytes in a congested blood vessel (red arrow)), (c) T1DM (glomerular collapse (yellow arrow) and blood stasis with well recognizable integral erythrocytes in a congested blood vessel (red arrow)), (d) T1DM-AMI (glomerular collapse (yellow arrow) and blood stasis with well recognizable integral erythrocytes in a congested blood vessel (red arrow)), (e) S-T1DM-CC-AMI (blood stasis (red arrow)), (f) CC-T1DM-CC-AMI (blood stasis (red arrow)), (g) S-T1DM-NC-AMI (blood stasis (red arrow)), (h) NC-T1DM-NC-AMI (normal architecture of the kidneys).

\subsection{Serum Levels of Matrix Metalloproteinases}

Serum levels of MMP-2 and MMP-9 increased after the induction of T1DM and AMI, with the highest levels in rats with T1DM and AMI (Figure 9).

All doses of CC and NC prevented the increase in MMP-2 (Figure 9a) and MMP-9 (Figure 9b). The best results were obtained for the two groups with curcumin nanoparticles compared to conventional curcumin for both matrix metalloproteinases (Figure 9, $p \leq 0.022$ ). MMP-2 levels were lower in rats who received the nanoparticles before T1DM induction than in rats who received curcumin nanoparticles after STZ administration (Figure 9a, $p=0.022$ ). No difference between the two groups with curcumin nanoparticles was observed for MMP-9 (Figure 9b, $p>0.05$ ). 


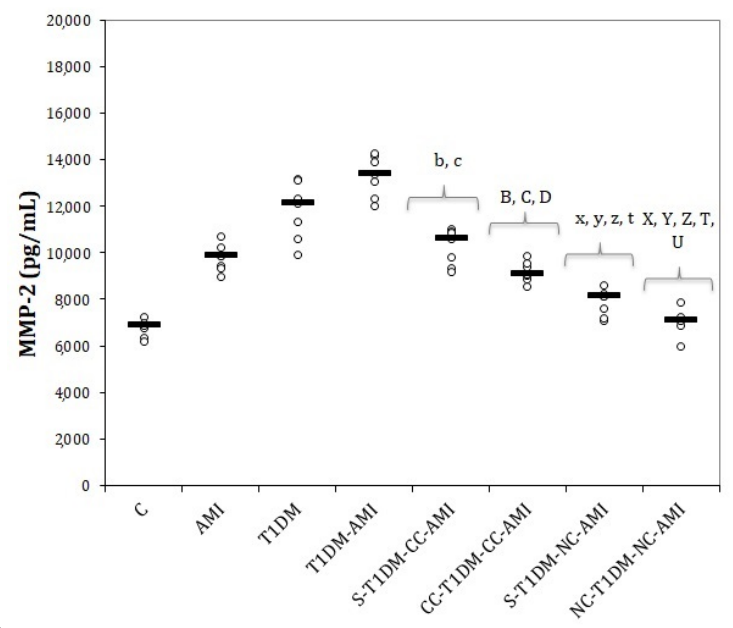

(a)

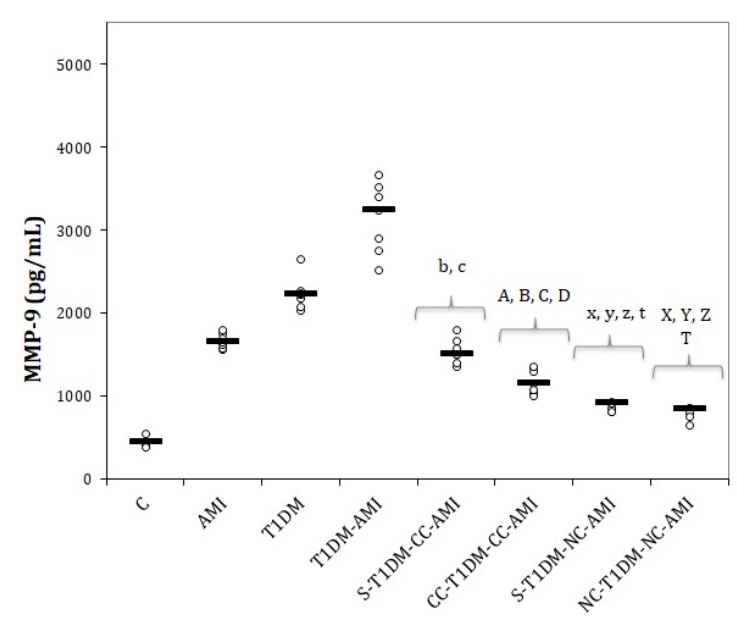

(b)

Figure 9. Serum levels of matrix metalloproteinases: (a) Matrix metalloproteinase 2 (MMP-2); (b) matrix metalloproteinase 9 (MMP-9). C—control; AMI—acute myocardial infarction; T1DM-type 1 diabetes mellitus; S-saline (0.09\%); CC— conventional curcumin solution (200 mg/Kg bw); NC—solution of curcumin nanoparticles (200 mg/Kg bw). The letters correspond to $p$ values <0.05: (b) S-T1DM-CC-AMI compared to T1DM; (c) S-T1DM-CC-AMI compared to T1DM-AMI; (A) CC-T1DM-CC-AMI compared to AMI; (B) CC-T1DM-CC-AMI compared to T1DM; (C) CC-T1DM-CC-AMI compared to T1DM-AMI; (D) CC-T1DM-CC-AMI compared to S-T1DM-CC-AMI; (x) S-T1DM-NP-AMI compared to AMI; (y) ST1DM-NP-AMI compared to T1DM; (z) S-T1DM-NP-AMI compared to T1DM-AMI; (t) S-T1DM-NP-AMI compared to S-T1DM-CC-AMI; (X) NP-T1DM-NP-AMI compared to AMI; (Y) NP-T1DM-NP-AMI compared to T1DM; (Z) NP-T1DMNP-AMI compared to T1DM-AMI; (T) NP-T1DM-NP-AMI compared to CC-T1DM-CC-AMI; (U) NP-T1DM-NP-AMI compared to S-T1DM-NP-AMI.

\section{Discussion}

\subsection{Serum Levels of Glucose and C-Peptide}

In our study, rats with STZ-induced T1DM, rats with ISO-induced AMI and all those with T1DM and AMI had a higher level of glucose (Figure 2). It was observed that acute hyperglycemia is characteristic for the early phase of AMI, even in patients without a history of T1DM, and that it exaggerates inflammation by the oxidative mechanism so that it can increase mortality [20]. Even more, hyperglycemia was observed to be capable of inducing electrophysiological alterations in myocardial tissue that might trigger fatal arrhythmias as a result of significant elongation of the QT interval [21].

Our results show that rats with STZ-induced T1DM had a lower level of C-peptide. C-peptide is widely used to measure the pancreatic beta-cell function of insulin secretion, as it is produced in equimolar amounts to endogenous insulin and is not influenced by therapeutically administered exogenous insulin [22]. Even if it was subsequently regarded as a waste product of insulin synthesis, since it does not affect glucose or lipid metabolism, new discoveries would support the idea that patients with T1DM who still have a certain degree of beta-cell activity are considerably less prone to develop microvascular complications compared to those with a total deficit of C-peptide [23].

Administration of curcumin to diabetic rats was reported to significantly reduce the plasma glucose level and increase plasma insulin and C-peptide levels substantially by promoting beta-cell regeneration [24]. Curcumin reduces the serum glucose level by stimulating insulin secretion of island $\beta$ cells [25]. It was already reported that nanocurcumin could reduce glucose level, pro-inflammatory cytokines, and oxidative stress in STZinduced T1DM due to decreased inflammation and apoptosis in pancreatic islets cells [26]. Better results obtained for NC can be explained by the increased tissue distribution of the curcumin nanoparticles in the body organs [27]. 


\subsection{Electrocardiogram Monitoring and Histological Changes of the Heart}

The cardiomyopathy described in the pathophysiology of STZ-induced T1DM is frequently associated with heart rhythm disturbances and contractile dysfunctions, as reduced contraction amplitude and prolonged time course of contraction and relaxation have been reported in cardiomyocytes from STZ-induced T1DM [28]. Howarth et al. reported that the ECG monitoring of diabetic rats after STZ administration revealed a reduction in HR and HR variability and prolonged QRS complex and QT intervals [29]. These results are similar to those obtained in our study (Figure 3, Table 1). Negative chronotropic effects and impairment of the sinoatrial node pointed to be responsible in HR reduction seen in STZ-induced diabetic rats are reversed by insulin treatment [30]. Prolongation of QT interval is considered to be associated with an increased risk of ventricular arrhythmias and/or sudden death. The autonomic neuropathy increases the risk of malignant arrhythmias and mortality rates, as it is correlated with a prolongation of the QT interval [31]. The underlying mechanisms involved in prolonging the QRS complex and QT interval in diabetes mellitus may include slowed inactivation and/or reductions in the activity of $\mathrm{Ca} 2+$ and $\mathrm{K}+$ channels of the cardiomyocytes membranes [29].

The reduction of the RR interval and increased HR recorded after ISO administration can be explained by the fact that ISO is a nonspecific $\beta$ adrenoreceptor agonist and by activation of $\beta$-adrenergic receptors increases the force of contraction of the left ventricle and accelerates the HR [32]. Rats with ISO-induced AMI presented a prolongation of the QRS complex, reduced R-wave amplitude, increased QT and QTc intervals, the elevation of the ST-segment, but had no effect on the PR segment (Figure 3, Table 1). As a result of the ISO cardiotoxic effect, slow ventricular conduction could explain the prolongation of the QRS complex and QT, QTc intervals [33]. The marked decrease in R-amplitude associated with elevation of ST-segment is indicative of AMI [34]. The decreased R-amplitude might result from the onset of myocardial edema following ISO administration, while the STsegment elevation reflects the loss of cardiomyocytes membrane function potential and the difference in action potentials in the boundary between the ischemic and non-ischemic zones of the myocardial tissue [34]. Our previous study reported that curcumin and curcumin nanoparticle doses increased the RR interval and reduced HR [35]. The exact mechanism of how curcumin reduces HR is not known yet and needs further investigations.

Pretreatment with curcumin was observed to protect the structure of the cardiomyocytes membrane, offering a cardioprotective effect against ECG alterations and acute fatal complications of AMI [36]. Preservation of cardiomyocytes structure and function could explain the reduction in the QRS complex enlargement after curcumin administration. The anti-inflammatory effects of curcumin and enhanced effects offered by curcumin nanoparticles could explain the reduction of edema in the myocardial tissue and prevention of the decreased $R$ wave $[35,37]$. Ranjan et al. observed that curcumin encapsulated in lipopolymer hybrid nanoparticle formulation increases the bioavailability and stability of the active compound offering a better protection against QT prolongation [38]. Helson et al. showed that liposomal curcumin better prevented QTc prolongation [39].

Curcumin administration, especially curcumin nanoparticles, reduced the area of cardiac necrosis, as curcumin can reduce the intensity of apoptosis and, therefore, decrease cardiomyocyte injury after AMI by modulating the immune cell filtration rate and improving the mitochondrial function of the injured cardiomyocytes [37].

\subsection{Serum Levels of Liver Function Parameters and Liver Histopathological Changes}

Rats with T1DM, and also those with AMI, presented elevated levels of hepatic necrosis enzymes, most high levels were seen in diabetic rats with AMI (Figure 5). Curcumin and curcumin nanoparticle administration reduced AST and ALT serum levels with lower levels for rats who received the NC before T1DM induction (Figure 5). Pretreatment with curcumin and curcumin nanoparticles had a hepatoprotective effect in high fructose streptozotocin-induced T2DM, by preventing ALT and AST elevation [40]. and they also 
reduced myocardial damage by preventing elevation of AST and ALT in AMI after ISO administration [35].

Streptozotocin administration led to multifocal micronecrosis, as streptozotocin administration is known to induce liver injuries [41]. Rats with AMI presented liver blood stasis, most probably due to acute cardiac dysfunction, while groups with T1DM and AMI presented lobular micronecrosis.

Curcumin administration reduced liver injury to focal necrosis (Figure 6). Rats who received curcumin nanoparticles administered after T1DM induction presented liver stasis, while rats who received curcumin nanoparticles from the beginning of the experiment had a normal aspect of the liver (Figure 6). These results can be explained by the fact that curcumin has a cellular membrane-stabilizing property so it reduces cellular destruction [42] Even more, curcumin seems to be able to reduce liver damage by inhibition of hepatic stellate cell (HSC) activation, as activation of HSC promotes liver fibrosis regardless of etiology [43].

\subsection{Serum Levels of Kidney Function and Kidney Histopathological Changes}

ISO administration caused a significant increase in urea levels without elevation of creatinine (Figure 7), indicating that the kidney damage, in this case, is most probably a pre-renal one (because of low cardiac output due to AMI), and it is not caused by intrinsic renal damage [42]. Diabetic rats showed an increase in the serum levels of creatinine and urea (Figure 7). Rats with T1DM and associated AMI presented the most elevated serum levels of kidney function parameters (Figure 7). Curcumin and curcumin nanoparticles prevented the elevation of these parameters (Figure 7).

The group with T1DM and the group with T1DM and AMI had glomerular collapse as this is one characteristic of diabetic nephropathy [44], while rats only with AMI presented glomerular stasis (Figure 8), most probably due to acute cardiac dysfunction. Curcumin administration reduced kidney histological damage to stasis (Figure 8). Similar results were observed in the group that received curcumin nanoparticles after STZ administration, while the group that received curcumin nanoparticles before STZ administration had a normal aspect of the kidney (Figure 8).

Curcumin administration improves renal function and preserves glomerular structure degeneration due to its antioxidative effects, as it decreases oxidative stress by reducing levels of subunits of nicotinamide adenine dinucleotide phosphate (NADPH), oxidase Nox4 and p67phox, which catalyzes the synthesis of $\mathrm{O}^{2-}$ and increases the activity of the antioxidant enzyme glutathione peroxidase. The nephroprotective effects of curcumin are also related to the downregulation of extracellular matrix protein fibronectin and collagen IV, and the inhibition of the profibrotic cytokines such as the vascular endothelial growth factor (VEGF), TGF- $\beta$, CTGF and osteopontin [45]. Better results obtained from encapsulated curcumin can result from the increased bioavailability and improved action of the active compound.

\subsection{Serum Levels of Matrix Metalloproteinases}

Conventional curcumin and NC prevented the increase in MMP-2 and MMP-9. The best results were obtained for $\mathrm{NC}$ compared to $\mathrm{CC}$, especially in rats who received the nanoparticles before T1DM induction (Figure 9).

Matrix metalloproteinases (MMPs) are a family of zinc-binding proteolytic enzymes that pathologically attack substrates as part of an inflammatory response and have an important role in the extracellular matrix (ECM) reorganization [46]. MMP-2, or gelatinase $\mathrm{A}$, is found in nearly all cell types and is involved in the degradation of denatured collagen and collagen type IV, a significant component of the basement membrane [47]. It may also be responsible for proteolysis of cytoskeletal proteins, increasing oxidative stress, so its inhibition can attenuate tissue damage [48]. MMP-9 is implicated in the regulation of tissue remodeling since it directly degrades extracellular matrix proteins and activates cytokines and chemokines involved in this process [49]. Apart from inflammation and oxidative 
stress, matrix MMPs can play an essential role in diabetes mellitus pathogenesis and contribute to vascular complications, especially in diabetic retinopathy due to the capillary cell apoptosis mechanism [50]. MMP-2 serum levels were reported to rise early in diabetes mellitus within the first 5 years from the onset of diagnosis and to be markedly raised with the disease's progression [51]. Elevated expression and enhanced activity of MMP-9 in diabetes mellitus is due to acute stimuli, such as vascular injury or as inflammatory mediators [52]. Systemic concentrations of MMP-2 and MMP-9, in addition to gelatinase activity levels, are also increased in patients with T2DM and peripheral arterial disease [53]. MMP-2 and MMP-9 are activated in the myocardial tissue after AMI's onset; therefore, they were studied for their roles in left ventricular remodeling and post-myocardial infarction prognosis [54]. Inhibition of MMP-2 was associated with a higher survival rate and with less left ventricular adverse remodeling after AMI in mice [54], while MMP-9 inhibition was associated with a lower incidence of myocardial wall rupture after AMI and reduced left ventricular dilation, explained by the reduced collagen reorganization in the infarcted area [55]. Curcumin treatment inhibits both MMP-2 and MMP-9 through its potent antioxidant and anti-inflammatory effect [56]. Curcumin nanoparticles were already proven effective in reducing MMP-2 and MMP-9 in streptozotocin-induced T1DM [57]. Our study is the first to report the effect of curcumin and curcumin nanoparticle pretreatment on MMP-2 and MMP-9 expression in AMI in rats with T1DM. Due to their ability to reduce the activity of active matrix metalloproteinases, curcumin and curcumin nanoparticles can be used as an adjuvant treatment for reducing the vascular complication of diabetes mellitus [57] and to improve systolic function and promotion of the cardiac remodeling process [56] after AMI in patients with diabetes mellitus. Curcumin nanoparticles exert greater effects on MMPs activity than curcumin due to their increased solubility and higher resistance to enzymatic degradation [57].

\section{Conclusions}

Curcumin nanoparticles administered before the induction of type 1 diabetes mellitus are more effective than conventional curcumin in maintaining cardiomyocyte function and structure in acute myocardial infarction, as they prevent the prolongation of the QRS complex, enlargement of QT and QTc intervals, ST-segment elevation, and they also reduce the area of myocardial necrosis.

Administration of curcumin nanoparticles before the induction of type 1 diabetes mellitus protects the beta cells, reduces serum glucose levels, and offers a higher level of C-peptide, better than conventional curcumin.

Pretreatment with conventional curcumin and curcumin nanoparticles provides a new perspective for therapeutic strategies in alleviating hepatic lesions related to streptozotocin and isoproterenol hepatotoxicity, as curcumin has a cellular membrane stabilizing property and reduces cellular destruction and secondary release of aspartate transaminase and alanine transaminase into the bloodstream, with best results for curcumin nanoparticles.

Pretreatment with conventional curcumin and curcumin nanoparticles provides beneficial effects in improving renal function in diabetic rats with acute myocardial infarction. Curcumin nanoparticles preserved normal histological aspects and better improved renal function biomarkers.

Curcumin and curcumin nanoparticles can be used as an adjuvant treatment to reduce the vascular complication of type 1 diabetes mellitus and improve systolic function and promotion of the cardiac remodeling process after acute myocardial infarction in subjects with type 1 diabetes mellitus.

Author Contributions: Conceptualization, P.-M.B., R.M.P., A.R. and S.D.B.; Data curation, R.M.P. and D.G.; Formal analysis, D.G., S.H.R., A.D.B. and S.D.B.; Funding acquisition, P.-M.B., R.M.P. and R.-M.R.; Investigation, P.-M.B., I.B., I.C.B., D.G. and S.D.B.; Methodology, I.B., A.E.B., S.H.R., A.D.B. and S.D.B.; Project administration, P.-M.B., I.B., D.G. and A.R.; Resources, A.E.B., I.C.B. and R.-M.R.; Software, I.C.B. and S.D.B.; Supervision, A.E.B. and Ș.H.R.; Validation, D.G.; Visualization, A.R.; 
Writing—original draft, P.-M.B. and Ș.H.R.; Writing—review and editing, R.-M.R., A.D.B. and S.D.B. All authors have read and agreed to the published version of the manuscript.

Funding: This research was funded by the "Iuliu Hațieganu" University of Medicine and Pharmacy, Cluj-Napoca, grant number/PCD number 1530/13/18.01.2019.

Institutional Review Board Statement: This study was approved by the Ethics Committee of the Iuliu Hatieganu University of Medicine and Pharmacy Cluj-Napoca (No. 53 from 22 January 2018) and by the Sanitary-Veterinary and Food Safety Directorate from Cluj-Napoca approval (No. 99 from 21st of February 2018).

Informed Consent Statement: Not applicable.

Data Availability Statement: The data obtained from the experiment can be obtained upon reasonable request addressed to Paul-Mihai Boarescu (e-mail: boarescu.paul@umfcluj.ro) and will be publicly available after publication of the associated PhD thesis.

Conflicts of Interest: The authors declare no conflict of interest.

\section{References}

1. Allender, S.; Scarborough, P.; Peto, V.; Rayner, M. European Cardiovascular Disease Statistics 2008; British Heart Foundation: London, UK, 2008.

2. Luo, M.; Guan, X.; Luczak, E.D.; Lang, D.; Kutschke, W.; Gao, Z.; Yang, J.; Glynn, P.; Sossalla, S.; Swaminathan, P.D.; et al. Diabetes increases mortality after myocardial infarction by oxidizing CaMKII. J. Clin. Investig. 2013, 123, 1262-1274. [CrossRef] [PubMed]

3. Classification and Diagnosis of Diabetes: Standards of Medical Care in Diabetes. 2019. Available online: https://care. diabetesjournals.org/content/diacare/42/Supplement_1/S13.full.pdf (accessed on 21 March 2021).

4. King, A.J.F. The use of animal models in diabetes research. Br. J. Pharmacol. 2012, 166, 877-894. [CrossRef] [PubMed]

5. Szkudelski, T. The mechanism of alloxan and streptozotocin action in B cells of the rat pancreas. Physiol. Res. 2001, 50, 537-546.

6. Rona, G. Catecholamine cardiotoxicity. J. Mol. Cell. Cardiol. 1985, 17, 291-306. [CrossRef]

7. Abd Halim, S.A.S.; Ghafar, N.A.; Jubri, Z.; Das, S. Induction of myocardial infarction in experimental animals: A review. J. Clin. Diagn. Res. 2018, 12, 1-5. [CrossRef]

8. Upaganlawar, A.; Gandhi, H.; Balaraman, R. Isoproterenol induced myocardial infarction: Protective role of natural products. J. Pharmacol. Toxicol. 2011, 6, 1-17. [CrossRef]

9. Mirzaei, H.; Shakeri, A.; Rashidi, B.; Jalili, A.; Banikazemi, Z.; Sahebkar, A. Phytosomal curcumin: A review of pharmacokinetic, experimental and clinical studies. Biomed. Pharmacother. 2017, 85, 102-112. [CrossRef]

10. Noorafshan, A.; Ashkani-Esfahani, S. A Review of Therapeutic Effects of Curcumin. Curr. Pharm. Des. 2013, 19, 2032-2046. [CrossRef]

11. Nelson, K.M.; Dahlin, J.L.; Bisson, J.; Graham, J.; Pauli, G.F.; Walters, M.A. The Essential Medicinal Chemistry of Curcumin. J. Med. Chem. 2017, 60, 1620-1637. [CrossRef]

12. Shang, L.; Nienhaus, K.; Nienhaus, G.U. Engineered nanoparticles interacting with cells: Size matters. J. Nanobiotechnology 2014, 12, 5. [CrossRef]

13. Hu, L.; Jia, Y.; Niu, F.; Jia, Z.; Yang, X.; Jiao, K. Preparation and Enhancement of Oral Bioavailability of Curcumin Using Microemulsions Vehicle. J. Agric. Food Chem. 2012, 60, 7137-7141. [CrossRef]

14. Panda, S.P.; Haldar, P.K.; Bera, S.; Adhikary, S.; Kandar, C.C. Antidiabetic and antioxidant activity of Swietenia mahagoni in streptozotocin-induced diabetic rats. Pharm. Biol. 2010, 48, 974-979. [CrossRef]

15. Bhandari, U.; Ansari, M.N. Ameliorative effect of an ethanol extract of Embelia ribes fruits on isoproterenol-induced cardiotoxicity in diabetic rats. Pharm. Biol. 2009, 47, 669-674. [CrossRef]

16. Boarescu, P.-M.; Boarescu, I.; Bocșan, I.C.; Gheban, D.; Bulboacă, A.E.; Nicula, C.; Pop, R.M.; Râjnoveanu, R.-M.; Bolboacă, S.D. Antioxidant and Anti-Inflammatory Effects of Curcumin Nanoparticles on Drug-Induced Acute Myocardial Infarction in Diabetic Rats. Antioxidants 2019, 8, 504. [CrossRef]

17. Dogaru, G.; Bulboaca, A.; Stanescu, I.; Rus, V.; Gyorgy, B.; Ciumarnean, L.; Munteanu, C.; Boarescu, P.M.; Neagos, A.; Festila, D. The effect of carbonated natural mineral water on oxidative stress in experimental myocardial ischemia. Rev. Chim. 2019, 70, 2677-2680. [CrossRef]

18. Konopelski, P.; Ufnal, M. Electrocardiography in rats: A comparison to human. Physiol. Res. 2016, 65, 717-725. [CrossRef]

19. Weissgerber, T.L.; Milic, N.M.; Winham, S.J.; Garovic, V.D. Beyond bar and line graphs: Time for a new data presentation paradigm. PLoS Biol. 2015, 13, e1002128. [CrossRef]

20. Ishihara, M. Acute hyperglycemia in patients with acute myocardial infarction. Circ. J. 2012, 76, 563-571. [CrossRef]

21. Ceriello, A. Acute hyperglycaemia, a 'new' risk factor during myocardial infarction. Eur. Heart J. 2004, 26, 328-331. [CrossRef] [PubMed]

22. Leighton, E.; Sainsbury, C.A.; Jones, G.C. A practical review of C-peptide testing in diabetes. Diabetes Ther. 2017, 8, 475-487. [CrossRef] 
23. Wahren, J.; Kallas, A.; Sima, A.A.F. The Clinical Potential of C-Peptide Replacement in Type 1 Diabetes. Diabetes 2012, 61, 761-772. [CrossRef] [PubMed]

24. Kusari, J.; Zhou, S.X.; Padillo, E.; Clarke, K.G.; Gil, D.W. Inhibition of vitreoretinal VEGF elevation and blood-retinal barrier breakdown in streptozotocin-induced diabetic rats by brimonidine. Investig. Ophthalmol. Vis. Sci. 2010, 51, 1044-1051. [CrossRef] [PubMed]

25. Wickenberg, J.; Ingemansson, S.L.; Hlebowicz, J. Effects of Curcuma longa (turmeric) on postprandial plasma glucose and insulin in healthy subjects. Nutr. J. 2010, 9, 43. [CrossRef]

26. Ganugula, R.; Arora, M.; Jaisamut, P.; Wiwattanapatapee, R.; Jørgensen, H.G.; Venkatpurwar, V.P.; Zhou, B.; Hoffmann, A.R.; Basu, R.; Guo, S.; et al. Nano-curcumin safely prevents streptozotocin-induced inflammation and apoptosis in pancreatic beta cells for effective management of Type 1 diabetes mellitus. Br. J. Pharmacol. 2017, 174, 2074-2084. [CrossRef]

27. Fang, M.; Jin, Y.; Bao, W.; Gao, H.; Xu, M.; Wang, D.; Wang, X.; Yao, P.; Liu, L. In vitro characterization and in vivo evaluation of nanostructured lipid curcumin carriers for intragastric administration. Int. J. Nanomed. 2012, 7, 5395-5404. [CrossRef]

28. Choi, K.M.; Zhong, Y.; Hoit, B.D.; Grupp, I.L.; Hahn, H.; Dilly, K.W.; Guatimosim, S.; Lederer, W.J.; Matlib, M.A. Defective intracellular Ca2+ signaling contributes to cardiomyopathy in Type 1 diabetic rats. Am. J. Physiol. Heart Circ. Physiol. 2002, 283, H1398-H1408. [CrossRef]

29. Howarth, F.C.; Jacobson, M.; Shafiullah, M.; Adeghate, E. Long-term effects of streptozotocin-induced diabetes on the electrocardiogram, physical activity and body temperature in rats. Exp. Physiol. 2005, 90, 827-835. [CrossRef] [PubMed]

30. Zhang, L.; Parratt, J.R.; Beastall, G.H.; Pyne, N.J.; Furman, B.L. Streptozotocin diabetes protects against arrhythmiasin rat isolated hearts: Role of hypothyroidism. Eur. J. Pharmacol. 2002, 435, 269-276. [CrossRef]

31. Veglio, M.; Chinaglia, A.; Cavallo-Perin, P. QT interval, cardiovascular risk factors and risk of death in diabetes. J. Endocrinol. Investig. 2004, 27, 175-181. [CrossRef]

32. Balea, Ş.S.; Pârvu, A.E.; Pop, N.; Marín, F.Z.; Pârvu, M. Polyphenolic Compounds; Antioxidant; and Cardioprotective Effects of Pomace Extracts from Fetească Neagră Cultivar. Oxid. Med. Cell. Longev. 2018, 2018, 8194721. [CrossRef] [PubMed]

33. Králová, E.; Mokran, T.; Murin, J.; Stankovicova, T. Electrocardiography in two models of isoproterenol-induced left ventricular remodeling. Physiol. Res. 2008, 57, S83-S89.

34. Soraya, H.; Khorrami, A.; Garjani, A.; Maleki-Dizaji, N.; Garjani, A. Acute treatment with metformin improves cardiac function following isoproterenol induced myocardial infarction in rats. Pharmacol. Rep. 2012, 64, 1476-1484. [CrossRef]

35. Boarescu, P.-M.; Boarescu, I.; Bocșan, I.C.; Pop, R.M.; Gheban, D.; Bulboacă, A.E.; Nicula, C.; Râjnoveanu, R.-M.; Bolboacă, S.D. Curcumin Nanoparticles Protect against Isoproterenol Induced Myocardial Infarction by Alleviating Myocardial Tissue Oxidative Stress, Electrocardiogram, and Biological Changes. Molecules 2019, 24, 2802. [CrossRef]

36. Nirmala, C.; Puvanakrishnan, R. Protective role of curcumin against isoproterenol induced myocardial infarction in rats. Mol. Cell. Biochem. 1996, 159, 85-93. [CrossRef] [PubMed]

37. Boarescu, P.M.; Chirilă, I.; Bulboacă, A.E.; Bocșan, I.C.; Pop, R.M.; Gheban, D.; Bolboacă, S.D. Effects of curcumin nanoparticles in isoproterenol-induced myocardial infarction. Oxid. Med. Cell. Longev. 2019, 2019, 7847142. [CrossRef]

38. Ranjan, A.P.; Mukerjee, A.; Helson, L.; Vishwanatha, J.K. Mitigating prolonged QT interval in canCer nanodrug development for accelerated clinical translation. J. Nanobiotechnol. 2013, 11, 40. [CrossRef]

39. Helson, L.; Shopp, G.; Bouchard, A.; Majeed, M. Liposome mitigation of curcumin inhibition of cardiac potassium delayed-rectifier current. J. Recept. Ligand Channel Res. 2012, 11, 1-8. [CrossRef]

40. Dogaru, G.; Bulboaca, A.E.; Gheban, D.; Boarescu, P.M.; Rus, V.; Festila, D.; Sitar-Taut, A.V.; Stanescu, I. Effect of liposomal curcumin on acetaminophen hepatotoxicity by down-regulation of oxidative stress and matrix metalloproteinases. In Vivo 2020, 34, 569-582. [CrossRef]

41. GezginCi-Oktayoglu, S.; Basaraner, H.; Yanardag, R.; Bolkent, S. The effects of combined treatment of antioxidants on the liver injury in STZ diabetic rats. Dig. Dis. Sci. 2009, 54, 538-546. [CrossRef] [PubMed]

42. Filho, H.G.L.; Ferreira, N.L.; De Sousa, R.B.; De Carvalho, E.R.; Lobo, P.L.D.; Filho, J.G.L. Experimental model of myocardial infarction induced by isoproterenol in rats. Braz. J. Cardiovasc. Surg. 2011, 26, 469-476. [CrossRef]

43. Buonomo, A.R.; Scotto, R.; Nappa, S.; Arcopinto, M.; Salzano, A.; Marra, A.M.; D'Assante, R.; Zappulo, E.; Borgia, G.; Gentile, I. The role of curcumin in liver diseases. Arch. Med. Sci. 2019, 15, 1608-1620. [CrossRef] [PubMed]

44. Trujillo, J.; Chirino, Y.I.; Molina-Jijón, E.; Andérica-Romero, A.C.; Tapia, E.; Pedraza-Chaverrí, J. Renoprotective effect of the antioxidant curcumin: Recent findings. Redox Biol. 2013, 1, 448-456. [CrossRef] [PubMed]

45. Lewandowski, K.C.; Banach, E.; Bieńkiewicz, M.; Lewiński, A. Matrix metalloproteinases in type 2 diabetes and non-diabetic controls: Effects of short-term and chronic hyperglycaemia. Arch. Med. Sci. 2011, 7, 294-303. [CrossRef] [PubMed]

46. Thompson, M.M.; Squire, I.B. Matrix metalloproteinase-9 expression after myocardial infarction: Physiological or pathological? Cardiovasc. Res. 2002, 54, 495-498. [CrossRef]

47. Sawicki, G.; Leon, H.; Sawicka, J.; Sariahmetoglu, M.; Schulze, C.J.; Scott, P.G.; Szczesna-Cordary, D.; Schulz, R. Degradation of myosin light chain in isolated rat hearts subjected to ischemia-reperfusion injury: A new intracellular target for matrix metalloproteinase. Circulation 2005, 112, 544-552. [CrossRef]

48. Yabluchanskiy, A.; Ma, Y.; Iyer, R.P.; Hall, M.E.; Lindsey, M.L. Matrix metalloproteinase-9: Many shades of function in cardiovascular disease. Physiology 2013, 28, 391-403. [CrossRef] [PubMed] 
49. Kowluru, R.A.; Mohammad, G.; Dos Santos, J.M.; Zhong, Q. Abrogation of MMP-9 gene protects against the development of retinopathy in diabetic mice by preventing mitochondrial damage. Diabetes 2011, 60, 3023-3033. [CrossRef] [PubMed]

50. Fouad, M.; Boraie, M. Matrix metalloproteinase-2 as potential marker of early nephropathy in type 1 diabetes. Am. J. Intern. Med. 2015, 3, 1-5. [CrossRef]

51. Uemura, S.; Matsushita, H.; Li, W.; Glassford, A.J.; Asagami, T.; Lee, K.H.; Harrison, D.G.; Tsao, P.S. Diabetes mellitus enhances vascular matrix metalloproteinase activity: Role of oxidative stress. Circ. Res. 2001, 88, 1291-1298. [CrossRef]

52. Signorelli, S.S.; Malaponte, G.; Libra, M.; Di Pino, L.; Celotta, G.; Bevelacqua, V.; Petrina, M.; Nicotra, G.S.; Indelicato, M.; Navolanic, P.M.; et al. Plasma levels and zymographic activities of matrix metalloproteinases 2 and 9 in type II diabetics with peripheral arterial disease. Vasc. Med. 2005, 10, 1-6. [CrossRef] [PubMed]

53. Hayashidani, S.; Tsutsui, H.; Ikeuchi, M.; Shiomi, T.; Matsusaka, H.; Kubota, T.; Imanaka-Yoshida, K.; Itoh, T.; Takeshita, A. Targeted deletion of MMP-2 attenuates early LV rupture and late remodeling after experimental myocardial infarction. Am. J. Physiol. Heart Circ. Physiol. 2003, 285, H1229-H1235. [CrossRef] [PubMed]

54. Ducharme, A.; Frantz, S.; Aikawa, M.; Rabkin, E.; Lindsey, M.; Rohde, L.E.; Schoen, F.J.; Kelly, R.A.; Werb, Z.; Libby, P.; et al. Targeted deletion of matrix metalloproteinase- 9 attenuates left ventricular enlargement and collagen accumulation after experimental myocardial infarction. J. Clin. Invest. 2000, 106, 55-62. [CrossRef] [PubMed]

55. Wang, N.P.; Wang, Z.F.; Tootle, S.; Philip, T.; Zhao, Z.Q. Curcumin promotes cardiac repair and ameliorates cardiac dysfunction following myocardial infarction. Br. J. Pharmacol. 2012, 167, 1550-1562. [CrossRef]

56. Bulboacă, A.E.; Porfire, A.S.; Tefas, L.R.; Boarescu, P.M.; Bolboacă, S.D.; Stănescu, I.C.; Bulboacă, A.C.; Dogaru, G. Liposomal Curcumin is Better than Curcumin to Alleviate Complications in Experimental Diabetic Mellitus. Molecules 2019, $24,846$. [CrossRef] [PubMed]

57. Nabofa, W.E.E.; Alashe, O.O.; Oyeyemi, O.T.; Attah, A.F.; Oyagbemi, A.A.; Omobowale, T.O.; Adedapo, A.A.; Alada, A.R.A. Cardioprotective Effects of Curcumin-Nisin Based Poly Lactic Acid Nanoparticle on Myocardial Infarction in Guinea Pigs. Sci. Rep. 2018, 8, 16649. [CrossRef] [PubMed] 